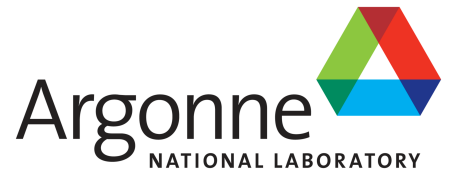

\title{
In-Sodium Testing of a Prototype Thermoacoustic Power Sensor for Sodium- Cooled Fast Reactors
}

Nuclear Science and Engineering Division 


\section{About Argonne National Laboratory}

Argonne is a U.S. Department of Energy laboratory managed by UChicago Argonne, LLC under contract DE-AC02-06CH11357. The Laboratory's main facility is outside Chicago, at 9700 South Cass Avenue, Argonne IL 60439. For information about Argonne and its pioneering science and technology programs, see www.anl.gov.

\section{DOCUMENT AVAILABILITY}

Online Access: U.S. Department of Energy (DOE) reports produced after 1991 and a growing number of pre-1991 documents are available free at OSTI.GOV (http://www.osti.gov/), a service of the US Dept. of Energy's Office of Scientific and Technical Information.

Reports not in digital format may be purchased by the public from the National Technical Information Service (NTIS):

U.S. Department of Commerce

National Technical Information

Service 5301 Shawnee Rd

Alexandria, VA 22312

www.ntis.gov

Phone: (800) 553-NTIS (6847) or (703) 605-6000

Fax: (703) 605-6900

Email: orders@ntis.gov

Reports not in digital format are available to DOE and DOE contractors from the Office of Scientific and Technical Information (OSTI):

U.S. Department of Energy

Office of Scientific and Technical Information

P.O. Box 62

Oak Ridge, TN 37831-0062

www.osti.gov

Phone: (865) 576-8401

Fax: (865) 576-5728

Email: reports@osti.gov

Disclaimer

This report was prepared as an account of work sponsored by an agency of the United States Government. Neither the United States Government nor any agency thereof, nor UChicago Argonne, LLC, nor any of their employees or officers, makes any warranty, express or implied, or assumes any legal liability or responsibility for the accuracy, completeness, or usefulness of any information, apparatus, product, or process disclosed, or represents that its use would not infringe privately owned rights.

Reference herein to any specific commercial product, process, or service by trade name, trademark, manufacturer, or otherwise, does not necessarily constitute or imply its endorsement, recommendation, or favoring by the United States Government or any agency thereof. The views and opinions of document authors expressed herein do not necessarily state or reflect those of the United States Government or any agency thereof, Argonne National Laboratory, or UChicago Argonne, LLC. 


\section{In-Sodium Testing of a Prototype Thermoacoustic Power Sensor for Sodium-Cooled Fast Reactors}

Prepared by

Hual-Te Chien, James J. Sienicki, Thomas W. Elmer, and William P. Lawrence

Nuclear Science and Engineering Division, Argonne National Laboratory

September 28, 2020 
This page intentionally left blank. 



\section{EXECUTIVE SUMMARY}

The ultimate goal of this project is to develop and demonstrate a thermoacoustic power sensor (TAPS) for Sodium-Cooled Fast Reactors (SFRs), with potential application also envisioned to other nuclear technologies such as Lead-Cooled Fast Reactors (LFRs), Molten Salt Reactors (MSRs), in addition to Light Water Reactors (LWRs). The project was led by Westinghouse Electric Company, LLC (Westinghouse) and carried out in collaboration with Argonne National Laboratory (ANL) and the University of Pittsburgh. A TAPS is a passive (self-powered), non-invasive (wireless) sensor envisioned for measuring key parameters, such as local temperature and neutron flux, in a nuclear reactor core. The sensor generates pressure waves (i.e., sound waves) with a frequency and amplitude dependent upon nuclear operating conditions (coolant temperature or power changes). The acoustic waves are able to travel through the core and associated structures, and reach to the sensor network placed outside and/or inside of the reactor vessel. These sensors require a very small amount of power which, during loss of power events, can be provided, for example, by harvesting gamma radiation energy, thus resulting in a monitoring system that can function both during normal operation and during loss of power events.

Westinghouse and the University of Pittsburgh designed and fabricated TAPS prototypes for Argonne National Laboratory (ANL) to carry out in-sodium testing to evaluate the effects of sodium on the TAPS and the performance of the TAPS technique in sodium. Argonne received a TAPS prototype from Westinghouse, and the prototype was modified such that it can be installed into a test vessel and function in sodium at elevated temperature without potentially leaking. A water mockup test apparatus was constructed to validate proper working of the prototype. An instrumentation and control (I\&C) system, running on the National Instruments (NI) LabView platform, was developed to: 1) operate both the water mockup test and the in-sodium test facility; and 2) process and analyze the received acoustic signals from an array of accelerometers and the Argonne sodium-submersible high-temperature acoustic sensor. The prototype was successfully tested in a water bath at different temperatures. Water mockup tests demonstrated that the TAPS prototype is working properly and its resonance frequency changes linearly with the coolant (water) temperature.

A TAPS test apparatus was constructed and integrated with the upgraded Under-Sodium Viewing (USV) sodium test facility. The integrated USV-TAPS sodium test facility has been operational. The TAPS prototype and a high-temperature sodium-submersible acoustic sensor (SSAS) developed by Argonne were both installed inside the TAPS test vessel. Being operated within argon cover gas under ambient conditions, the TAPS prototype demonstrated that it was functioning properly with a resonance frequency at 1407.2 $\mathrm{Hz}$, which was successfully detected by the accelerometers mounted on the external wall of the vessel and the high-temperature SSAS installed inside the vessel.

After successfully transferring sodium into the vessel, in-sodium tests of the prototype were conducted. Tests of the TAPS prototype demonstrated that the resonance frequency of the TAPS changes linearly with respect to the temperature difference between the interior of the TAPS and bulk sodium. The early tests showed that the TAPS prototype could not establish a continuous and consistent resonance in sodium. The resonance diminished before the prototype reached its operating temperature. A signal postprocessor was added to the DAQ module latterly to isolate interferences, enhance signal conditioning, improve peak detection, and generate resonance frequency versus temperature plots. After testing in molten sodium and immersion at higher temperature for several weeks, the TAPS prototype was able to establish a continuous resonance. 
Performance evaluation of the TAPS prototype was then conducted in sodium. The tests included the investigation of 1) the effects of the temperature difference between the TAPS and bulk sodium, 2) the effects of sodium flowrate; and 3) the performance of the different sensor-receiver systems positioned inside or outside the vessel. Results of a test demonstrated that, with limited sodium circulation, a continuous and consistent resonance of the TAPS prototype was established occasionally. The tests also demonstrated that, because of the nature of detection principles and mounting methods, the hightemperature SSAS is more affected by acoustic noise, while accelerometers are more affected by vibrations, in the test environment.

It is unknown why the TAPS prototype only occasionally established a continuous and consistent resonance when the TAPS temperature reached its operating temperature in molten sodium, and why it ultimately failed to resonate at all. A failure modes assessment was conducted and a few potential causes of failure were identified. Different post in-sodium tests were conducted to obtain additional information potentially relevant to the cause of the failure. Nondestructive evaluation techniques are suggested to examine the internal integrity as well as the gas mixture of the prototype. If they prove inconclusive, the prototype should be cut open to conduct a thorough inspection of its internal integrity and determine the state of the gas mixture. 


\section{Acknowledgments}

Argonne is a U.S. Department of Energy Laboratory managed by UChicago Argonne, LLC under contract DE-AC02-06CH11357. The work reported here was sponsored by the U.S. Department of Energy (DOE) Office of Nuclear Energy's Advanced Reactor Technologies (ART) program. The TAPS team would like to thank Mr. Christopher Grandy for his guidance and technical direction throughout the course of this effort. A special acknowledgement of thanks goes to Mr. Brian Robinson and Mr. Thomas Sowinski, Fast Reactor Program Managers for the DOE-NE ART program, during this work and to Dr. Robert Hill, the National Technical Director for Fast Reactors for the DOE-NE ART program, for their consistent support of the Advanced Concepts work. A special gratitude to our collaboration team, especially to Mr. Michael Heibel, Mr. Jorge Carvajal, and Dr. Paolo Ferroni of Westinghouse Electric Company, LLC, and Professor Jeffrey Vipperman of the University of Pittsburgh, for their crucial role of the design and fabrication of a TAPS prototype as well as valuable assistance and suggestions. 
This page intentionally left blank. 


\section{Acronyms and Abbreviations}

$\begin{array}{ll}\text { A/D } & \text { Analog-to-Digital } \\ \text { ANL } & \text { Argonne National Laboratory } \\ \text { ART } & \text { Advanced Reactor Technology } \\ \text { C\&D } & \text { Control and Display } \\ \text { DAQ } & \text { Data Acquisition } \\ \text { DOE } & \text { U.S. Department of Energy } \\ \text { DOE-NE } & \text { Office of Nuclear Energy in the Department of Energy } \\ \text { FY } & \text { Fiscal Year } \\ \text { HT } & \text { High Temperature } \\ \text { I\&C } & \text { Instrumentation and Control } \\ \text { ISHM } & \text { In-Sodium Hydrogen Meter } \\ \text { LFR } & \text { Lead-Cooled Fast Reactor } \\ \text { LWR } & \text { Light Water Reactor } \\ \text { MSR } & \text { Molten Salt Reactor } \\ \text { NI } & \text { National Instruments } \\ \text { SFR } & \text { Sodium-Cooled Fast Reactor } \\ \text { SSAS } & \text { Sodium-Submergible Acoustic Sensor } \\ \text { SMS } & \text { Signal Measuring System } \\ \text { SS } & \text { Stainless Steel } \\ \text { TAPS } & \text { Thermoacoustic Power Sensor } \\ \text { TC } & \text { Thermocouple } \\ \text { USV } & \text { Under-sodium Viewing }\end{array}$


This page intentionally left blank. 


\section{Contents}

EXECUTIVE SUMMARY i

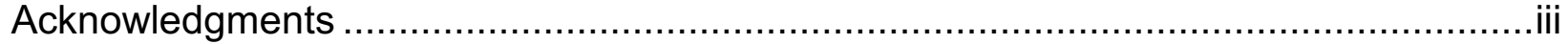

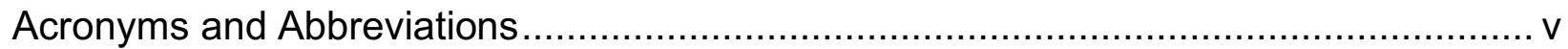

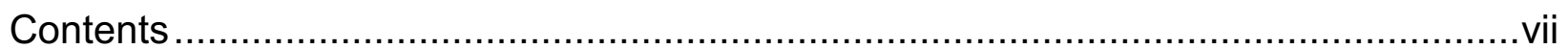

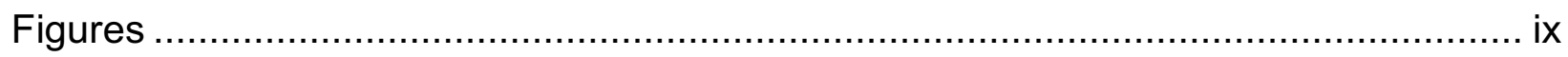

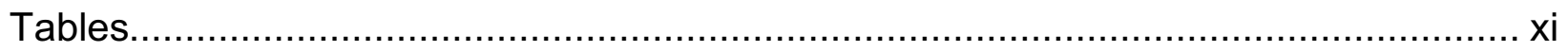

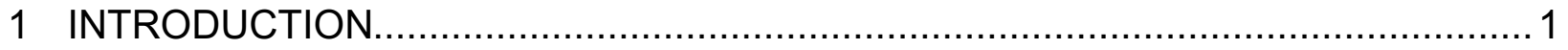

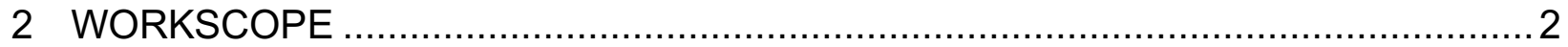

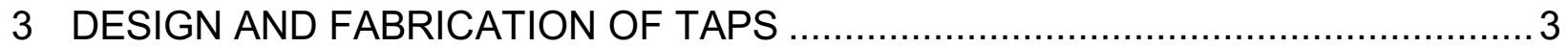

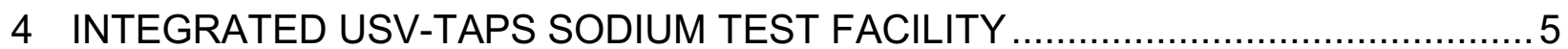

4.1 Design of Integrated USV-TAPS Sodium Test Facility................................. 5

4.2 Construction of Integrated USV-TAPS Sodium Test Facility ........................... 9

4.3 Installations of Sensor Array and TAPS Prototype....................................... 10

$5 \quad$ IN-SODIUM TESTING OF THE TAPS PROTOTYPE ......................................... 11

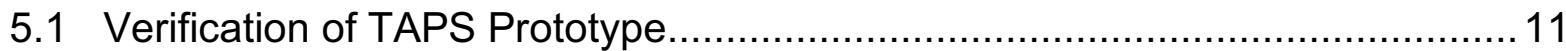

5.2 In-Sodium Prototype Testing and Performance Evaluation............................. 13

5.2.1 In-Sodium Test of TAPS in Solid Sodium ......................................... 13

5.2.2 In-Sodium Test of TAPS in Molten Sodium ........................................ 17

5.2.3 In-Sodium Test of TAPS with Continuous Resonance ......................... 19

6 POST IN-SODIUM TESTS AND FAILURE MODES ASSESSMENT …....................23

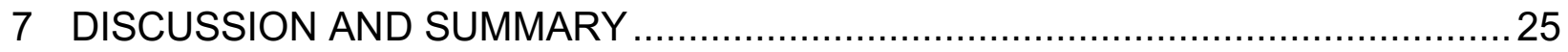

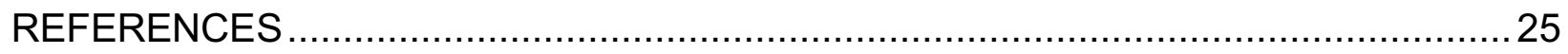


This page intentionally left blank. 


\section{Figures}

Figure 1. Sketches of the TAPS Assembly design: (left) resonator; (top-right) hot end; (bottom-right) cold end [1].

Figure 2. Photograph of TAPS prototype for in-sodium performance evaluation. ......................... 4

Figure 3. Diagram of integrated USV-TAPS sodium test facility .............................................. 5

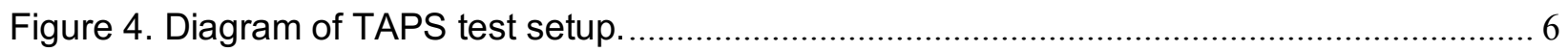

Figure 5. Mounting locations of accelerometers.......................................................................... 7

Figure 6. Control and display (C\&D) panel of the TAPS I\&C system: (top-left) DAQ control; (top-right) sodium and TAPS temperatures; (bottom-left) spectrum;

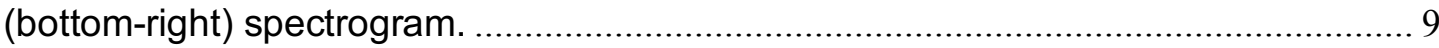

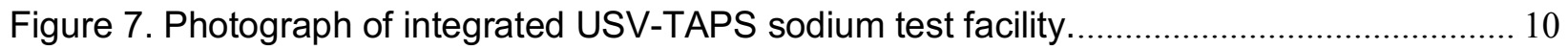

Figure 8. Photograph of TAPS test setup.................................................................................. 11

Figure 9. Spectrogram of the TAPS acquired by SSAS in cover gas under ambient

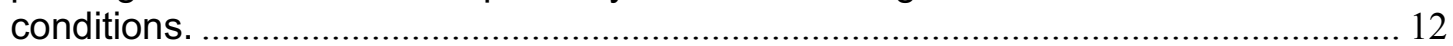

Figure 10. Spectrogram of the TAPS acquired by SSAS in sodium at $76.8^{\circ} \mathrm{C} \ldots \ldots \ldots \ldots \ldots \ldots \ldots . . . . . . . . . . . . .12$

Figure 11. Bulk sodium and TAPS temperatures (top right), spectrum (bottom left), and spectrogram (bottom right) acquired by SSAS in sodium after postprocessing........ 14

Figure 12. Resonance frequency with respect to temperature difference between TAPS and bulk sodium in sodium at $76.8^{\circ} \mathrm{C}$.

Figure 13. Postprocessed spectrograms acquired by SSAS and accelerometers in sodium at $76.8^{\circ} \mathrm{C}$.

Figure 14. Sodium and TAPS temperatures (top right), spectrum (bottom left), and spectrogram (bottom right) of the TAPS acquired by SSAS in sodium at $45.2^{\circ} \mathrm{C}$.

Figure 15. Resonance frequency versus temperature difference between TAPS and bulk sodium in solid sodium at $45.2^{\circ} \mathrm{C}$.

Figure 16. Postprocessed spectrograms acquired by SSAS and accelerometers in solid sodium at $45.2^{\circ} \mathrm{C}$

Figure 17. Bulk sodium and TAPS temperatures, spectrogram, spectrum, and resonance of TAPS detected by accelerometer \#4 in sodium after postprocessing of test TAPS-LT2.

Figure 18. Resonant frequencies of two consecutive tests with respect to temperature difference between TAPS and bulk sodium in molten sodium at $128.4^{\circ} \mathrm{C}$.

Figure 19. Spectrograms acquired by SSAS and accelerometers in molten sodium at $128.4^{\circ} \mathrm{C}$

Figure 20. Bulk sodium and TAPS temperatures (top right), spectrum (bottom left), and spectrogram (bottom right) acquired by SSAS in sodium at $51.5^{\circ} \mathrm{C}$.

Figure 21. Bulk sodium and TAPS temperatures, spectrum, and spectrogram, of TAPS prototype detected by accelerometer \#4 in sodium after postprocessing of test TAPS-LT2 
Figure 22. Spectrograms of the TAPS acquired by SSAS and accelerometers of test TAPS-LT2.

Figure 23. TAPS's temperature and spectrograms acquired by accelerometer \#4 for eight different tests in sodium at $51.5^{\circ} \mathrm{C}$.

Figure 24. Resonant frequencies acquired by accelerometer \#4 of in-sodium TAPS tests. ....... 23 


\section{Tables}

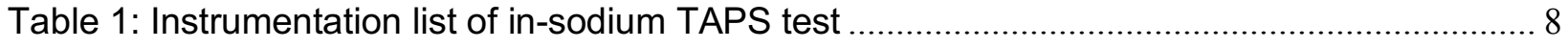

Table 2: Operating Condition and Signal Quality of TAPS Tested in Sodium ........................... 20 
This page intentionally left blank. 


\section{INTRODUCTION}

For operation optimization, cost efficiency, and safety, it is important to measure and monitor the operating conditions in real-time of a nuclear reactor core. The Thermoacoustic Power Sensor (TAPS) is a selfpowered, wireless sensor that could be used for real-time, in-situ measurement of key parameters, such as local temperature and neutron flux, in a harsh environment, such as the reactor core of a Sodium-Cooled Fast Reactor (SFR), Lead-Cooled Fast Reactor (LFR), Molten Salt Reactor (MSR), in addition to Light Water Reactors (LWRs). The wireless TAPS is also applicable for in-situ temperature monitoring of dry casks for used fuel storage. TAPS is essentially a thermoacoustic engine that is encapsulated inside an instrumentation tube and heated by an integral nuclear-powered heater, for example, either a fuel pellet or a gamma-harvesting material. The instrumentation tube consists of a heat source (hot end), a ceramic stack, and an acoustic resonator (cold end) and is filled with a noble gas mixture. The acoustic (sound) waves, generated by the thermoacoustic effect, propagate through the reactor coolant and through the reactor core and associated structures, and then are measured by acoustic sensors located on the outside and/or inside of the reactor vessel. The wireless-transmitted acoustic signal is then amplified, filtered, and processed by a signal conditioning and data acquisition (DAQ) system. The sound wave amplitude corresponds to the local radiation flux in the core, and the resonance frequency is proportional to the local coolant temperature. The sensor array of TAPSs distributed throughout a reactor core is envisioned to provide wireless, realtime measurements of the local coolant temperature and neutron flux conditions as a function of position.

The ultimate objective of this project is to develop and demonstrate the TAPS technique for in-situ, realtime reactor power and core temperature monitoring of an SFR. For an SFR, the core inlet temperature and outlet temperature can vary from 350 and $500^{\circ} \mathrm{C}$, respectively, to 400 and $550^{\circ} \mathrm{C}$, respectively. The sodium temperature in testing should thus be varied over this range. In an SFR, there is an upward coolant flow over the fuel pins. If a TAPS is substituted for a fuel pin, then it will also be exposed to an upward coolant flow. Thus, a suitable upward sodium flow should be provided in testing. An SFR contains fuel pin, wirewrap, hexcan, and in-vessel structures. Ultimately, the effects of such structures should be simulated. However, in-sodium testing may be carried out without the structure, in order to characterize the TAPS output and signal transmission without the effects of intervening structures.

The current workscope includes five major tasks for in-sodium testing and performance evaluation of a TAPS prototype supplied by Westinghouse Electric Company, LLC (Westinghouse). This report documents the initial testing of the TAPS prototype in sodium. Section 2 lists the FY20 workscope and Section 3 reports the design and fabrication of a TAPS prototype. Section 4 documents the construction of the TAPS test apparatus and its integration with the Argonne USV sodium test facility. The TAPS test apparatus consists of a test vessel, a TAPS prototype, an accelerometer array, a high-temperature sodiumsubmergible acoustic sensor (SSAS), heating devices, a temperature control unit, and an instrumentation and control (I\&C) unit.

Section 5 documents the performance evaluation of the TAPS prototype tested in molten sodium. After leak testing of the apparatus, the prototype and the SSAS, and an accelerometer array were successfully tested and verified working properly in the test vessel filled with cover gas. After sodium was introduced into the test vessel, the prototype was verified working properly, its resonance frequency was verified, and its onset points of thermoacoustic effects at different sodium temperatures and electric heater temperatures were evaluated. Section 6 presents the discussion and conclusions of the development and in-sodium testing of the TAPS technique for in-situ power/temperature measurement for an SFR. References cited in this report are then listed. 


\section{WORKSCOPE}

The workscope for this project includes the following five major tasks proposed:

\section{Tap Testing:}

Tap testing was suggested by Westinghouse to identify the fully-coupled resonant frequencies of the vibroacoustic system constituted by the vessel, TAPS, fluid, vessel supporting structure, etc. This involves before and after introducing sodium to the vessel, using an impulse hammer to tap at designated input points on the vessel structure and nearby the accelerometers. The vibrational modes of the structural-acoustic system are expected to be temperature-dependent, and direct measurement allows for corroboration of the Finite Element Analysis (FEA) modeling of the vibrational modes, and post processing operational TAPS test data.

\section{Signal Optimization:}

This involves determining the optimal signal conditioning, including amplification, filtering, and processing according to the operating condition and resonance frequency range.

\section{TAPS Prototype Verification:}

After introducing sodium to the TAPS test vessel, using accelerometers and the Argonne high-temperature acoustic sensor to 1) verify that the TAPS prototype works properly, 2) verify resonance frequency of the TAPS prototype, and 3) determine the onset points of thermoacoustic effects at different sodium temperatures and electric heater temperatures (or input power).

\section{In-Sodium Pilot Testing and Performance Evaluation}

The task includes the evaluation of the sensitivity, response time, and reproducibility of the TAPS prototype under different power settings of the electric heater, different sodium flowrates, and different sodium temperatures. The prototype was to be tested without and with the pump with the sodium temperature ramped up and down between $200^{\circ} \mathrm{C}$ and $343^{\circ} \mathrm{C}\left(392^{\circ} \mathrm{F}\right.$ and $\left.650^{\circ} \mathrm{F}\right)$.

\section{Sensor Optimization}

Based on results of the in-sodium pilot testing, Argonne will conduct a sensor optimization to recommend, for example, the optimal resonance, a calibration procedure (if needed), and the optimal operating conditions for the development of a TAPS array that is applicable for its implementation in an SFR. 


\section{DESIGN AND FABRICATION OF TAPS}

This section provides a brief introduction to physics, design, and potential benefits of TAPS technology when applied to nuclear reactors. A history of the research and development of the TAPS technique and the mathematical description of TAPS basic principles were described in a previous report [1]. TAPS technology serves as a mechanism to convert thermal energy to acoustic energy. TAPS is essentially a thermoacoustic engine that is encapsulated inside an instrumentation tube, i.e. an acoustic resonator. It internally consists of a heat source (hot end), a ceramic stack, and an acoustic resonator (cold end), and is usually filled with a noble gas mixture [2]. For consistent heating and better reproducibility, a TAPS usually uses a passive nuclear-powered heating source, for example, either a fuel pellet or a gamma-harvesting material which eliminates the use of any electric wires and enables the sensor to be wireless, as well as extends the life expectancy of the sensor. When heat is introduced to a TAPS at the hot end, the heat is transferred by electromagnetic (EM) radiation to the stack located in between the hot and cold ends of the TAPS. Because of the temperature gradient between the hot and cold ends, larger-scale molecular motion of the filled gas then oscillates across the stack and produces standing thermoacoustic waves that ultimately "ring out" at its acoustic natural frequencies. The acoustic waves will then propagate through the reactor coolant (sodium) and through the reactor core structure, and are measured by acoustic sensors located on the outside of the reactor vessel. The wireless-transmitted acoustic signal is then amplified, filtered, and processed by a signal conditioning and data acquisition (DAQ) system. The sound wave amplitude corresponds to the local radiation flux in the core, and the wave frequency is proportional to the local coolant temperature. An array of TAPSs distributed throughout a reactor core is envisioned to provide wireless, real-time measurements of the local coolant temperature and neutron flux conditions as a function of position.

In conjunction with exploration of the SFR application, Westinghouse developed a full set of functional requirements for the (1) TAPS sensor hardware, (2) TAPS Signal Measurement System (SMS) hardware and software, and (3) the TAPS testing program [3]. Based on the mathematical model of thermoacoustic effects and the requirements for in-sodium testing at the Argonne Under-Sodium Viewing (USV)-TAPS facility, Westinghouse designed a TAPS prototype for in-sodium testing in the USV facility [2]. For laboratory pilot testing, an electrical heater was used to simulate the passive heating device. Its housing was also modified for easy installation or remove. Figure 1 shows sketches of the TAPS Assembly design for sodium application, which proceeded as an evolution of the original hardware developed for a synergistic LWR program [1]. In addition, the improvements included a thermal core with improved efficiency and simpler, more robust fabrication methods. The prototype consists of eight main components: TAPS shell, ceramic stack, electrical heater, isolation springs, insulation cap, slotted tubing, holding assembly, and thermocouple (TC). The specifications and details of the components were reported in Ref. 2. Figure 2 shows a photograph of a TAPS prototype manufactured by Mirion IST for in-sodium performance evaluation. 

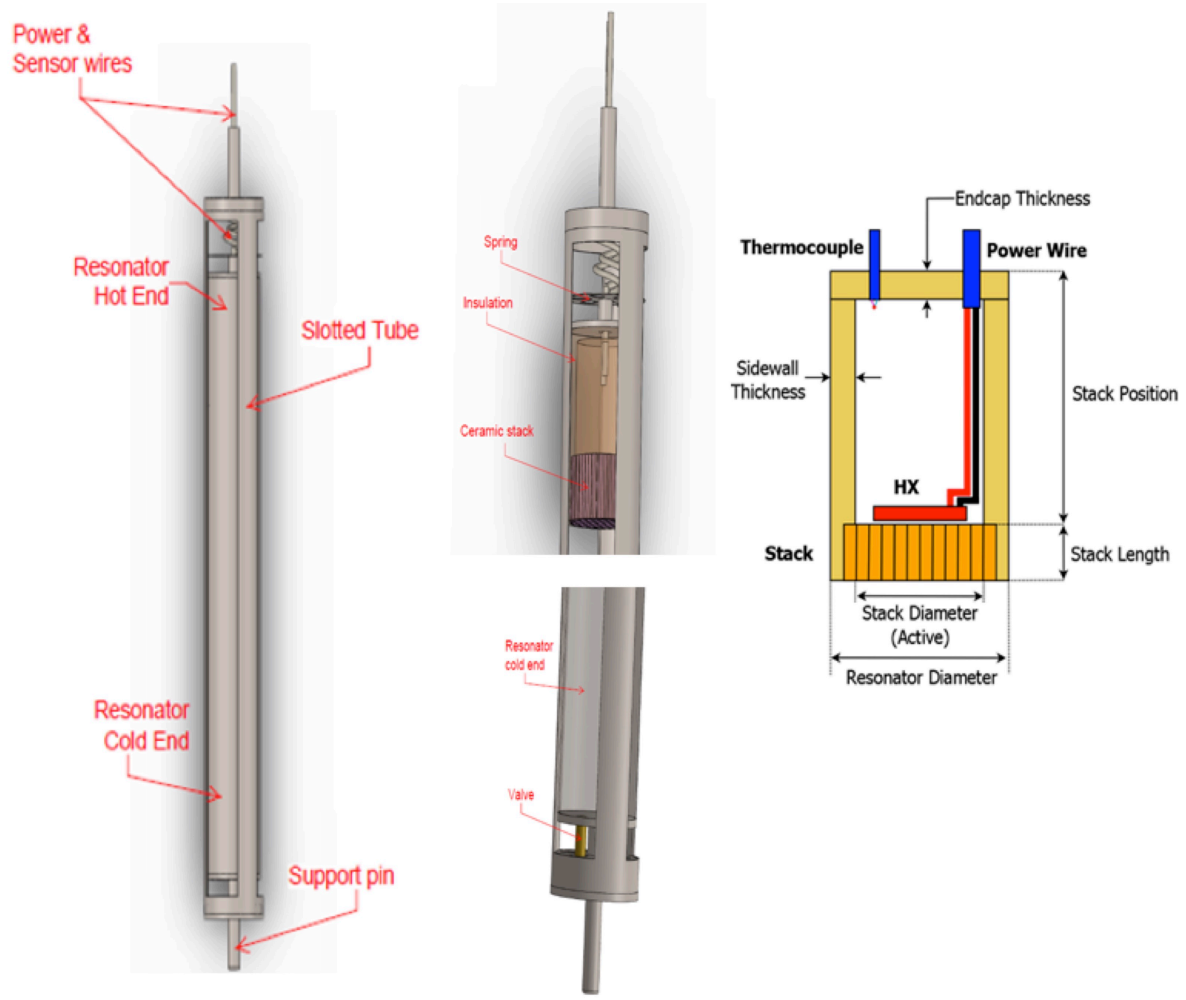

Figure 1. Sketches of the TAPS Assembly design: (left) resonator; (top-right) hot end; (bottomright) cold end [1].

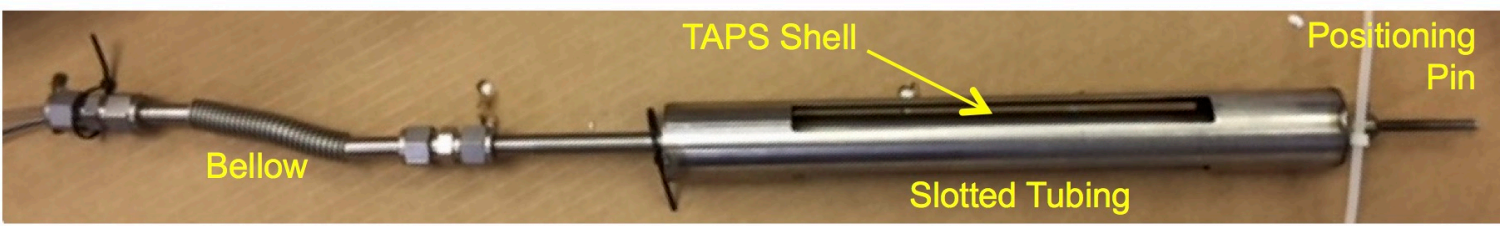

Figure 2. Photograph of TAPS prototype for in-sodium performance evaluation. 


\section{INTEGRATED USV-TAPS SODIUM TEST FACILITY}

The TAPS, developed by Westinghouse, potentially could be used for real-time core temperature/power monitoring of an SFR. To demonstrate the TAPS technique in a sodium environment, a TAPS test apparatus was designed and constructed in FY19 [2]. This section documents the integration of the TAPS test apparatus with the Argonne USV sodium test facility for in-sodium tests of a TAPS prototype supplied by Westinghouse.

\subsection{Design of Integrated USV-TAPS Sodium Test Facility}

The USV sodium test facility was modified to accommodate the new TAPS and In-Sodium Hydrogen Meter (ISHM) test apparatuses. To be operated independently, both test apparatuses were branched from the USV sodium loop. The TAPS test apparatus consists of four major units: TAPS test vessel, temperature control module, acoustic sensor array, and I\&C unit. Figure 3 shows a diagram of the integrated USV-TAPS sodium test facility.

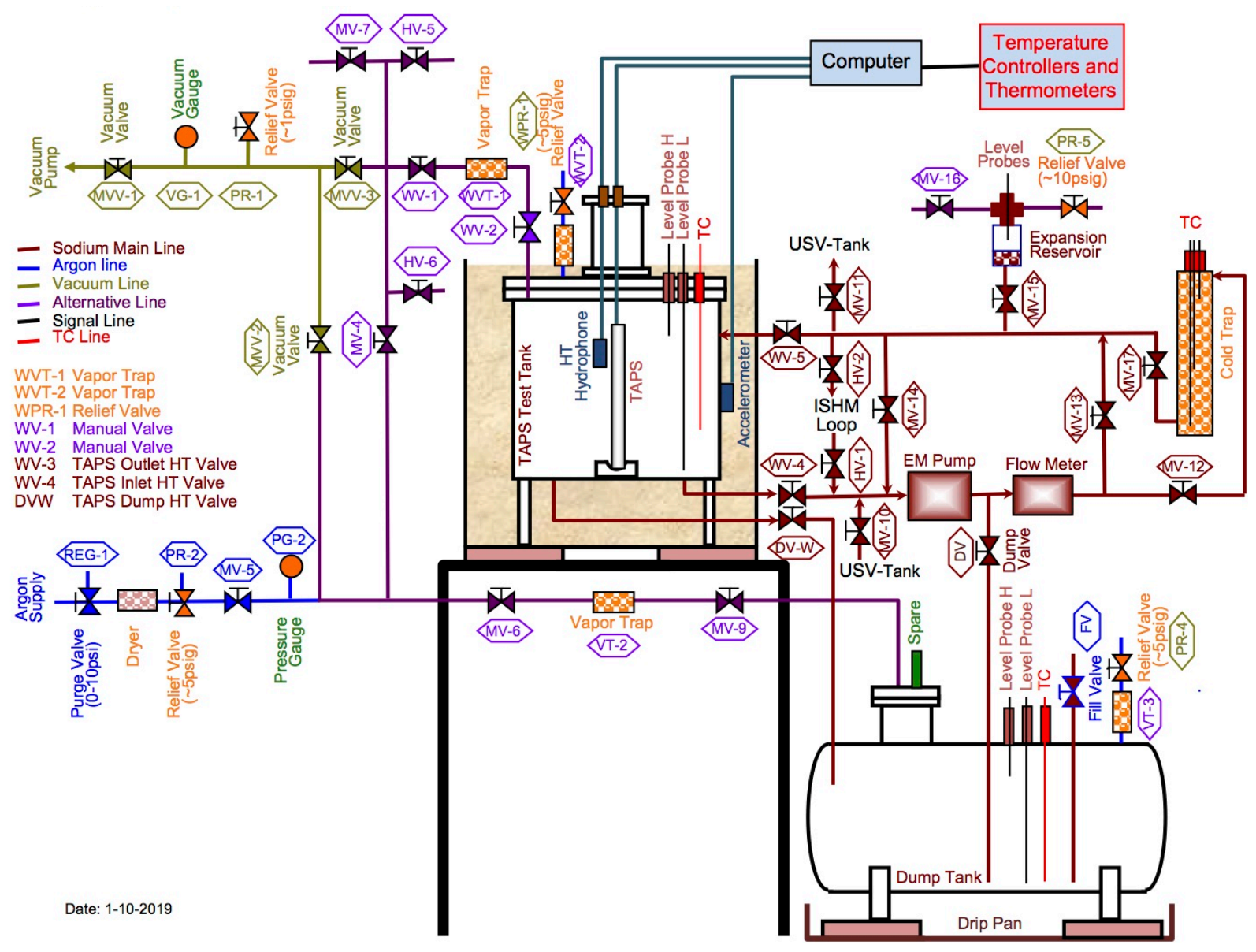

Figure 3. Diagram of integrated USV-TAPS sodium test facility.

\section{TAPS Test Vessel:}

The TAPS test vessel, 12" in diameter and 19.5" in height, was built and tested according to ASME Code Section VIII and is ASME Code stamped to be operated up to $343^{\circ} \mathrm{C}\left(650^{\circ} \mathrm{F}\right)$ and $30 \mathrm{psig}$. This is the same 
temperature to which the TAPS-USV facility is approved to operate. The TAPS test vessel consists of a high temperature (HT) sodium filling/dumping valve, two shut-off valves for sodium input and output, and a top flange assembly. Through the two shut-off valves, the apparatus can be used to control a test under isolated or pumped flow mode, or isolated from the USV sodium loop for service.

The top flange assembly of the vessel consists of a cover flange, an extension cap, a cap cover flange, and six feedthroughs for sodium level probes, K-type thermocouple (TC), pressure relief valve, and cover gas/vacuum line. The three conductive level sensors, sealed by a graphite compression seal, fed through the cover flange, are set for low, fill, and high. The TAPS prototype is installed through the top cover flange and the extension cap, which allows the prototype to be lifted out of the liquid sodium and removed from the test vessel without sodium draining nor opening the cover flange that might cause sodium contamination. Figure 4 shows a diagram of the dimensions of the test vessel and the setup of a TAPS prototype inside the vessel.

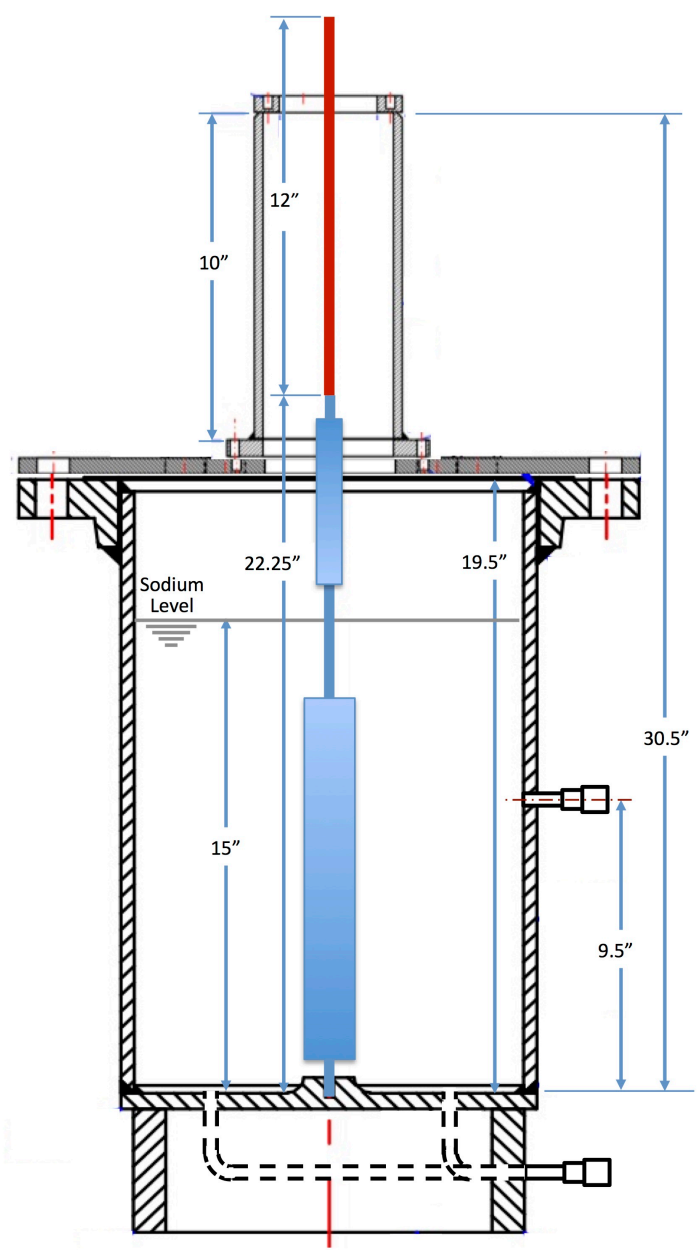

Figure 4. Diagram of TAPS test setup.

\section{Temperature Control Module:}

A temperature control module was constructed to control and monitor the sodium temperature in the test vessel and pipelines, and the internal temperature of the TAPS prototype. Fiberglass trace heaters (HTS/Amptek, up to $900^{\circ} \mathrm{F}$ ) are mounted on the outer walls of the vessel body and all the pipelines and valves. Each is controlled and monitored by a PID temperature controller (HTS/Amptek Model BBA-200), 
respectively. The internal heater of the TAPS prototype is controlled by a variable linear DC power supply (VOLTEQ Model HY3005D-3) for a precise continuous adjustment.

\section{Acoustic Sensor Array:}

An array of accelerometers and a high-temperature SSAS are used to monitor the resonance frequency generated by the TAPS prototype. For optimal signal reception or sensor sensitivity, ten accelerometers (PCB 357B61) were mounted on the external wall of the vessel body, bottom, and top flange at designed locations according to the modelling conducted by the University of Pittsburg, to measure the acoustic resonance generated by the TAPS prototype. A high-temperature SSAS developed at Argonne was inserted into the sodium through a feedthrough on the top flange. Figure 5 shows the mounting locations of the ten accelerometers.

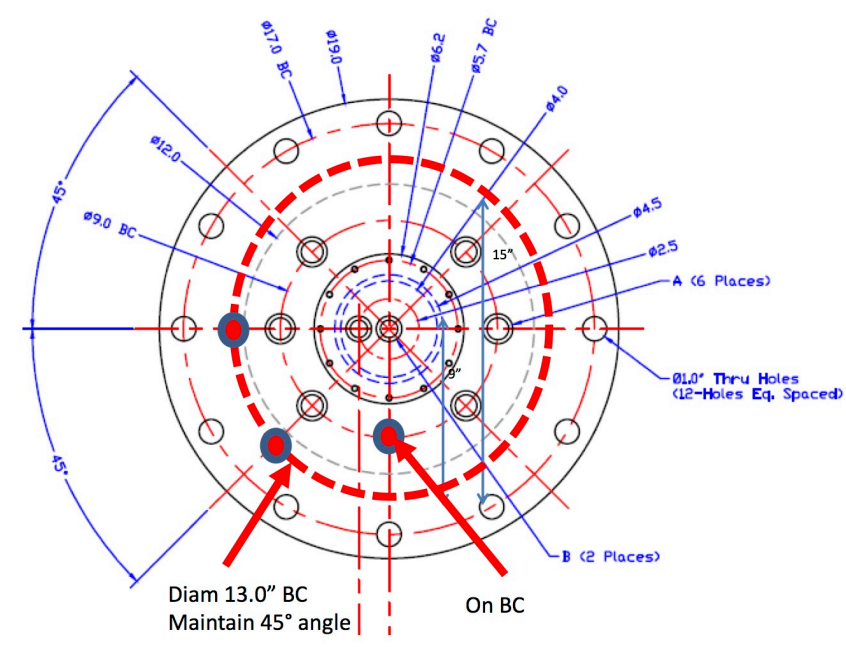

(a) Flange

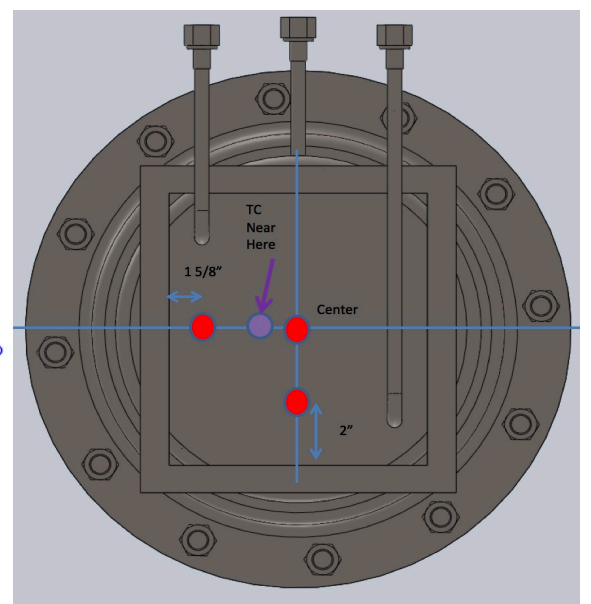

(b) Bottom

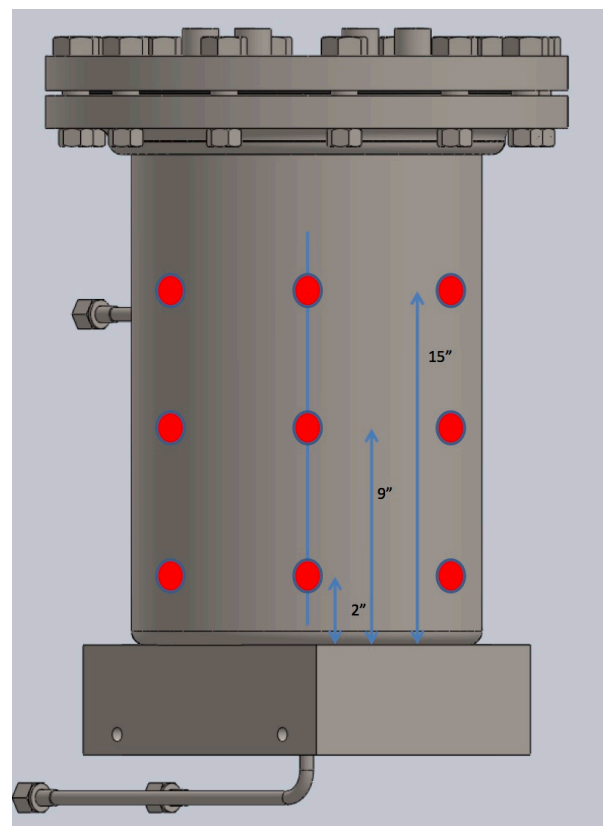

(c) Body

Figure 5. Mounting locations of accelerometers. 
Instrumentation and Control Unit:

An instrumentation and control $(\mathrm{I} \& \mathrm{C})$ unit was developed to operate the integrated USV-TAPS sodium test facility. The system consists of four major modules: flow control, signal conditioning, DAQ, and control and display (C\&D). The functionalities of the three modules are described as the following:

- Flow control module: This module controls and monitors the sodium flow during an in-sodium test under the pumped flow mode. It consists of an EM sodium pump (CMI Novacast Model CA-15) to generate a sodium flowrate up to $5 \mathrm{gal} / \mathrm{min}$ and an EM sodium flowmeter (CMI Novacast Model FS15) to monitor sodium flowrate. The TAPS apparatus is isolated from the USV sodium loop when tested under stagnant mode. Under the pumped flow mode, molten sodium is circulated through the USV-TAPS sodium loop by the EM pump.

- Signal conditioning: This module measures, amplifies, and filters the received acoustic signals (i.e. the resonance frequency) generated by the TAPS and detected by the sensor array (accelerometers and acoustic sensor) before feeding to DAQ module. Table 1 lists the signal conditioning instruments used for in-sodium TAPS testing.

- DAQ module: This model consists of an eight-channel compactDAQ unit (NI Model cDAQ 9178) and a DAQ computer. After signal conditioning, each received acoustic signal is fed to an analog-to-digital (A/D) converter unit (NI Model 9215), respectively. The temperatures of the TAPS probe and the sodium within the test vessel are also measured by K-type thermocouples, respectively, and digitized by a TC unit (NI Model 9213). The compactDAQ unit then transfers the digitized acoustic signals and temperatures to the DAQ computer, which processes and analyzes the received acoustic signals, then obtains the acoustic amplitude and resonance frequency of the TAPS probe at the operating (sodium) temperature. The DAQ instruments are also listed in Table 1.

Table 1: Instrumentation list of in-sodium TAPS test

\begin{tabular}{|c|c|c|}
\hline Name & Model & Specifications \\
\hline Charge Accelerometer & PCB 357B61 & $\begin{array}{l}10 \text { pico-Columbus ( } \mathrm{pC} \text { ) per gram, } \mathrm{T}_{\max } \text { : } \\
482^{\circ} \mathrm{C} / 900^{\circ} \mathrm{F}, 5 \mathrm{KHz}\end{array}$ \\
\hline In-line Charge Converter & PCB 422E36 & $10 \mathrm{mV} / \mathrm{pC}, \pm 2.5 \mathrm{~V}, 121^{\circ} \mathrm{C} / 250^{\circ} \mathrm{F}$ \\
\hline Charge Amplifier & PCB MOD 462A & \\
\hline Dual Filter & DL 4302 & Dual $24 \mathrm{~dB} /$ octave, $10 \mathrm{~Hz}-1 \mathrm{MHz}$ \\
\hline Sensor Signal Conditioner & PCB 483C41 & 8 Channels, Sensor: ICP ${ }^{\circledR}$, Charge, Voltage \\
\hline Eight-Slot USB Chassis & NI cDAQ 9178 & $0-10 \mathrm{MHz}$ \\
\hline Analog Input Module & NI 9215 & $\begin{array}{l}4 \mathrm{Al}, \pm 10 \mathrm{~V}, 16 \text { Bit, } 100 \text { kilo-samples per } \\
\text { second per channel simultaneous }\end{array}$ \\
\hline Thermocouple Module & NI 9213 & $\begin{array}{l}16 \mathrm{TC}, \pm 78 \mathrm{mV}, 24 \mathrm{Bit}, 75 \text { samples per } \\
\text { second Aggregate }\end{array}$ \\
\hline DC Power Supply & VOL TEQ HY3005D-3 & Dual Channels, $0-30$ VDC, $0-5 \mathrm{~A}$ \\
\hline
\end{tabular}

Control and Display (C\&D) module: This module controls and displays the operating parameters of the TAPS frequency analysis as well as of the NI A/D converting units used in the DAQ module, such as channels and data acquisition rate (delay). The module then displays the acoustic spectrogram of the TAPS 
with respect to it temperature. Figure 6 shows a screenshot of the C\&D panel of the I\&C unit running on LabView ${ }^{\mathbb{R}}$ platform. The top-left of the panel shows the DAQ control of the NI units and their operating parameters; top-right shows temperatures of sodium in the test vessel and electric heater of the TAPS; bottom-left shows spectrum of the received acoustic signal and TAPS resonance frequency; and bottomright shows the spectrogram. Spectrum and spectrogram of the SSAS and seven accelerometers can be displayed by changing the input signal selection.

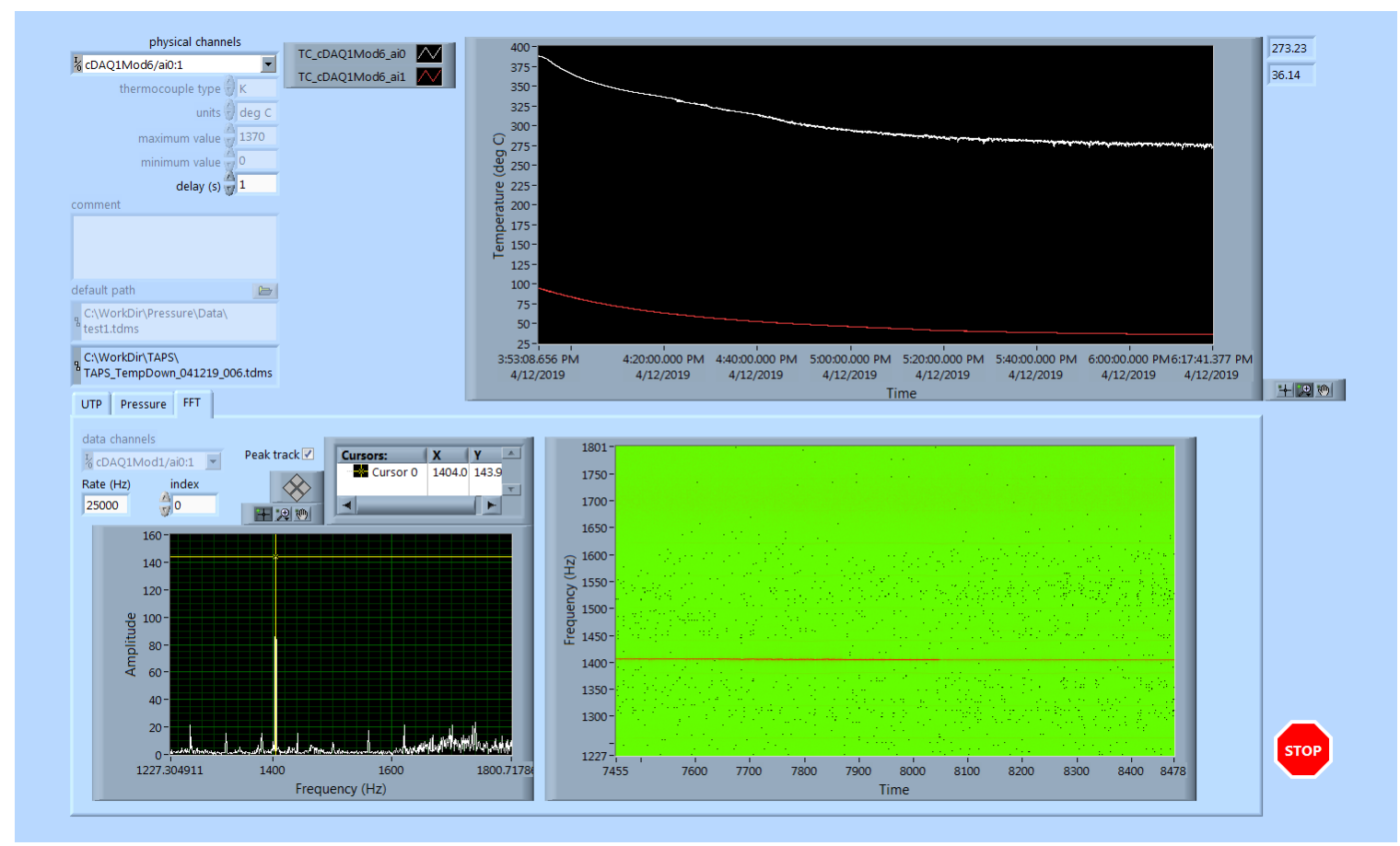

Figure 6. Control and display (C\&D) panel of the TAPS I\&C system: (top-left) DAQ control; (topright) sodium and TAPS temperatures; (bottom-left) spectrum; (bottom-right) spectrogram.

\subsection{Construction of Integrated USV-TAPS Sodium Test Facility}

The integrated USV-TAPS sodium test facility was constructed and is located in the Building 308 HighBay at Argonne. The TAPS test vessel was placed in a stainless steel (SS) secondary container (28.5" width $\times 30$ " diameter $\times 30.5$ " height). VCR fittings are used between all the connections that would be in contact with molten sodium. Unplated nickel gaskets (NI-8-VCR-2-VS or NI-8-VCR-2-GR-VS) are used for all the VCR fitting connections supplied by Swagelok. All the valves that would be in contact with molten sodium are bellows-sealed valves welded with VCR fitting end connections supplied by Swagelok (SS$8 \mathrm{UW}-\mathrm{HT}-\mathrm{V} 47)$ of $480 \mathrm{psig} @ 1,200^{\circ} \mathrm{F}\left(648^{\circ} \mathrm{C}\right)$. Fiberglass trace heaters (HTS/Amptek, up to $\left.900^{\circ} \mathrm{F}\right)$ are mounted on the outer walls of the vessel body and all the pipelines and valves. PID temperature controllers (HTS/Amptek Model BBA-200) are used to control and monitor the temperatures of the test vessel and pipelines. Figure 7 shows a photograph of the integrated USV-TAPS sodium test facility, before piping insulation, with an ISHM test apparatus that is being added on the left side. 


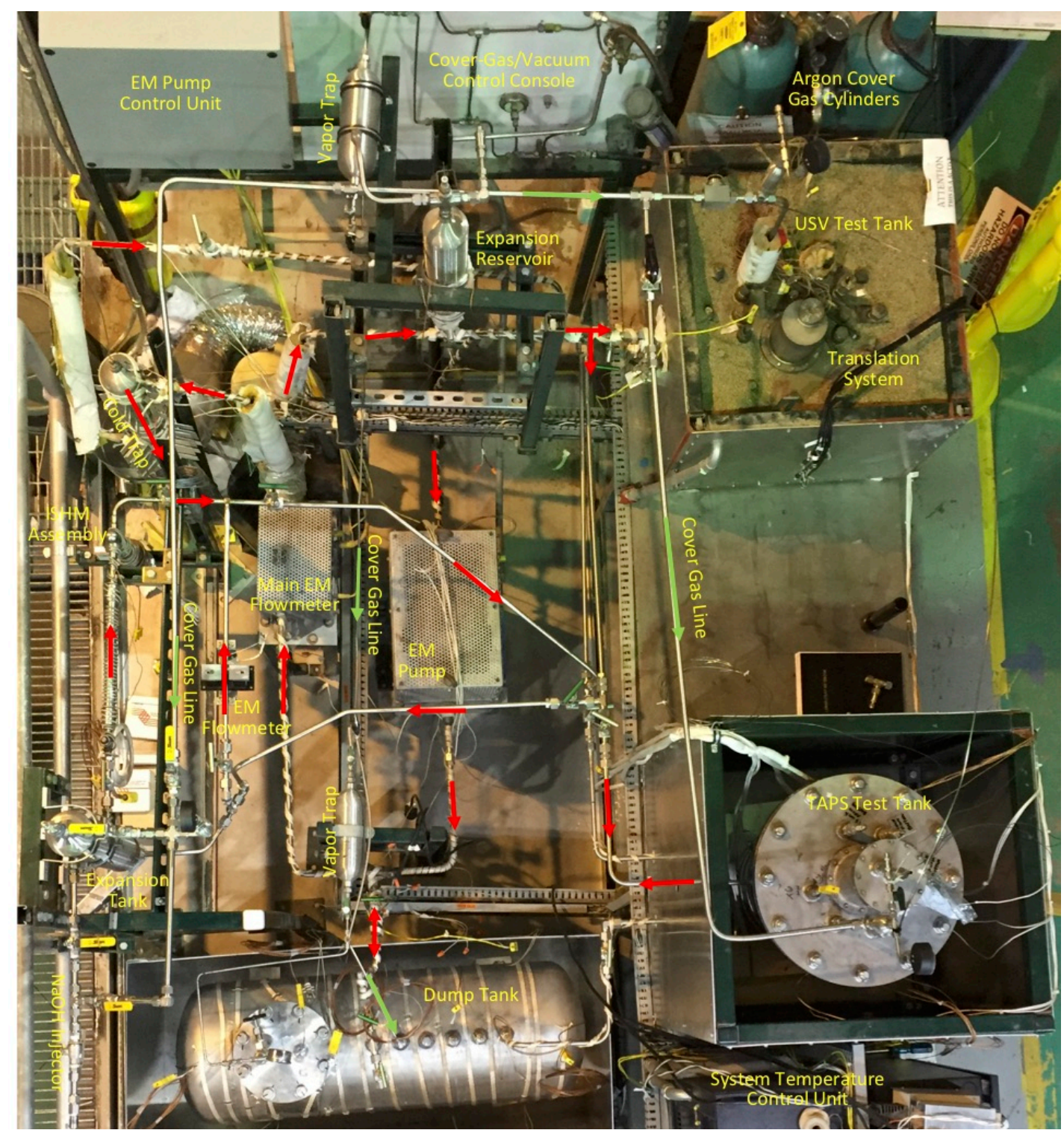

Figure 7. Photograph of integrated USV-TAPS sodium test facility.

\subsection{Installations of Sensor Array and TAPS Prototype}

A pin was welded at the bottom of the TAPS prototype for sensor alignment and support to avoid potential vibration caused by sodium flow. The TAPS prototype was then installed into the test vessel through the center feedthrough on the cover cap flange of the top flange assembly. The setup of a TAPS prototype inside the test vessel was shown in Figure 4. Level sensors, TCs, and SSAS were also installed through the feedthroughs on the cover flange. To minimize the probability of modal influences between the resonances of the TAPS and the test vessel, ten accelerometers with stainless steel (SS) mounting bases were mounted at the designated locations (Figure 5) suggested by the modal analysis conducted by the University of Pittsburg. Trace heaters were then mounted on the test vessel. Figure 8 shows a photograph of the setup of the TAPS test vessel. The TAPS test apparatus was sealed and leak-tested to hard vacuum. After filling the secondary containment with vermiculite, the apparatus was baked out at $250^{\circ} \mathrm{C}$ under vacuum. 


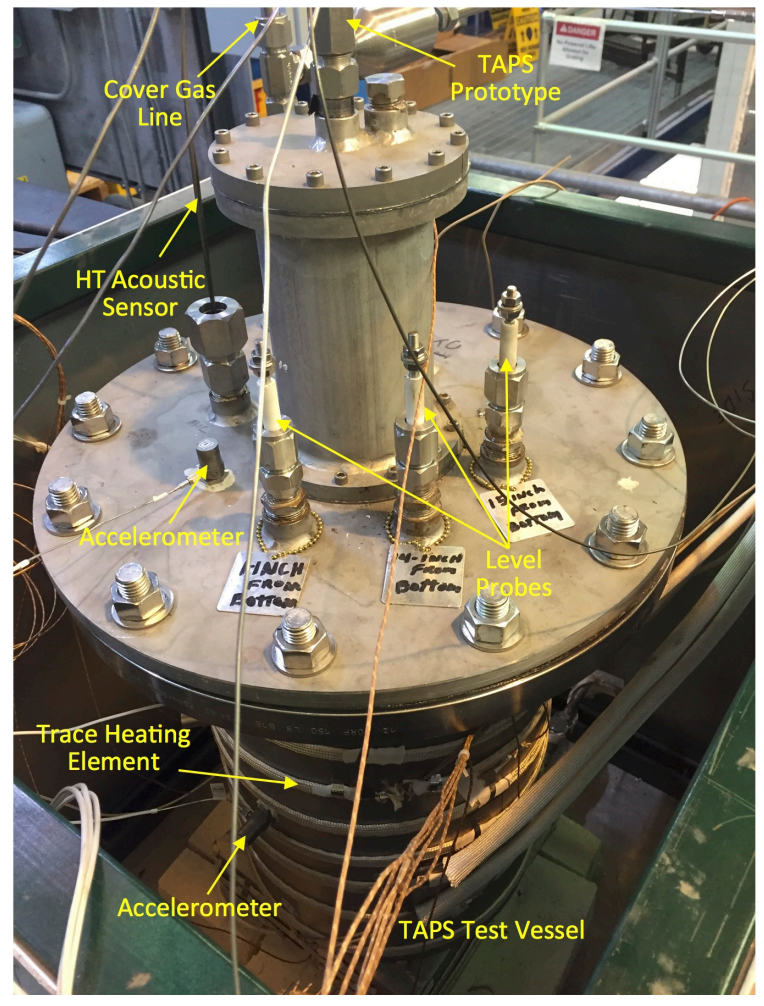

Figure 8. Photograph of TAPS test setup.

\section{$5 \quad$ IN-SODIUM TESTING OF THE TAPS PROTOTYPE}

The TAPS, developed by Westinghouse, potentially could be used for real-time core temperature/power monitoring of an SFR. This section documents the in-sodium testing and performance evaluation of a TAPS prototype in a sodium environment. The operating temperature, i.e. the operating resonance frequency, of a TAPS is determined by its heating source, which is consistently set at a designated level. When reaching its designated operating temperature, the prototype then establishes a continuous resonance. The resonance frequency will shift linearly with the temperature change of the cold end of the prototype, i.e. the coolant temperature. Before and after sodium was introduced into the test vessel, tests were successfully conducted to verify if the TAPS prototype and the high-temperature SSAS were working properly, as well as to optimize the signal conditioning and DAQ setups. In-sodium tests of the prototype were then conducted.

\subsection{Verification of TAPS Prototype}

After being inserted into the TAPS test vessel and before introducing sodium into the vessel, preliminary tests of the TAPS prototype were conducted to verify that the TAPS prototype and the SSAS were operating properly. The tests also determined the setups of the I\&C unit for signal conditioning and DAQ optimizations for TAPS in-sodium testing. After leak testing of the apparatus, the prototype and SSAS were tested with the test vessel filled with cover gas under ambient conditions. The test demonstrated that the accelerometers and the SSAS both measured the TAPS resonance frequency at $1,407.2 \mathrm{~Hz}$ and confirmed that they were working properly. Figure 9 shows the spectrogram of the prototype detected by the SSAS inside the test vessel filled with cover gas under ambient conditions. The TAPS was able to 
generate a continuous and consistent resonance at $1407.2 \mathrm{~Hz}$ when the prototype was operated at $590^{\circ} \mathrm{C}$ continuously.

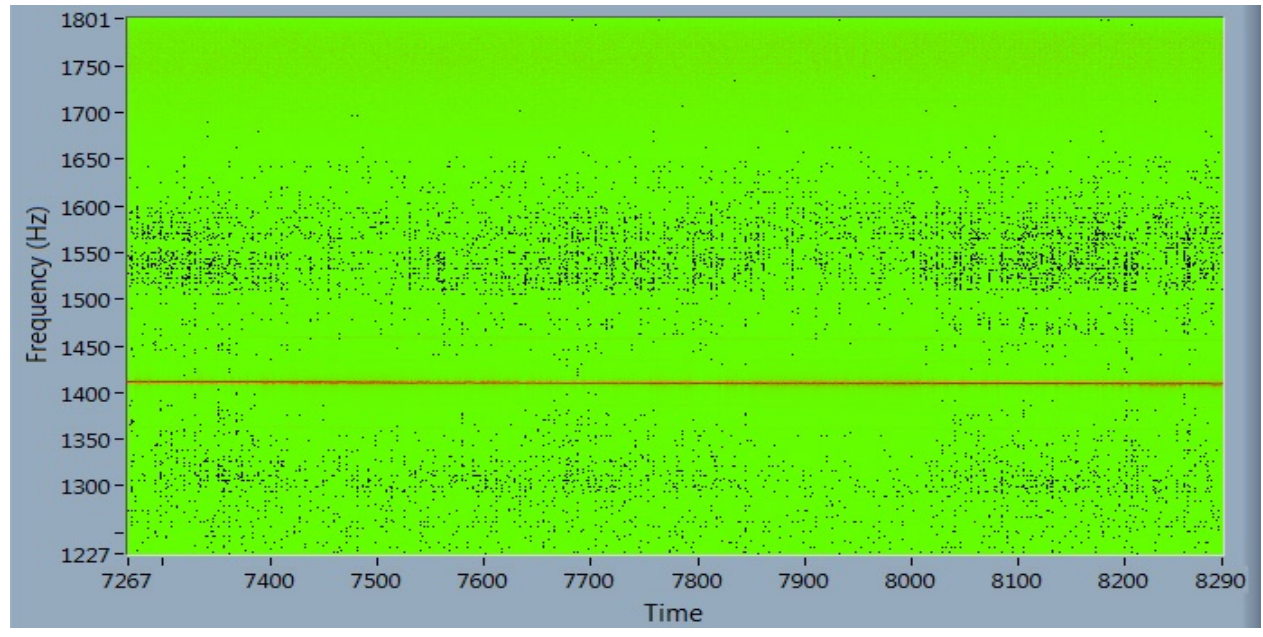

Figure 9. Spectrogram of the TAPS acquired by SSAS in cover gas under ambient conditions.

After introducing sodium to the TAPS test vessel, accelerometers and the Argonne high-temperature SSAS were used to 1) verify that the TAPS prototype works properly, 2) verify resonance frequency of the TAPS prototype, and 3) determine the onset points of thermoacoustic effects at different sodium temperatures and electric heater temperatures (or input power). The prototype was tested in sodium at a sodium temperature of $76.8^{\circ} \mathrm{C}$ with the DC power supply set at $13.1 \mathrm{~V}$ and $4.93 \mathrm{~A}$. The SSAS and all seven accelerometers were tested and confirmed working properly. Figure 10 shows a spectrogram acquired by the SSAS for testing in sodium. It shows onset of resonance of the prototype at $1,213.2 \mathrm{~Hz}$, when the temperature of the TAPS hot-end reached $199.4^{\circ} \mathrm{C}$. The resonant frequency increased to $1,256.5 \mathrm{~Hz}$, when the temperature of the TAPS hot-end reached $527^{\circ} \mathrm{C}$.

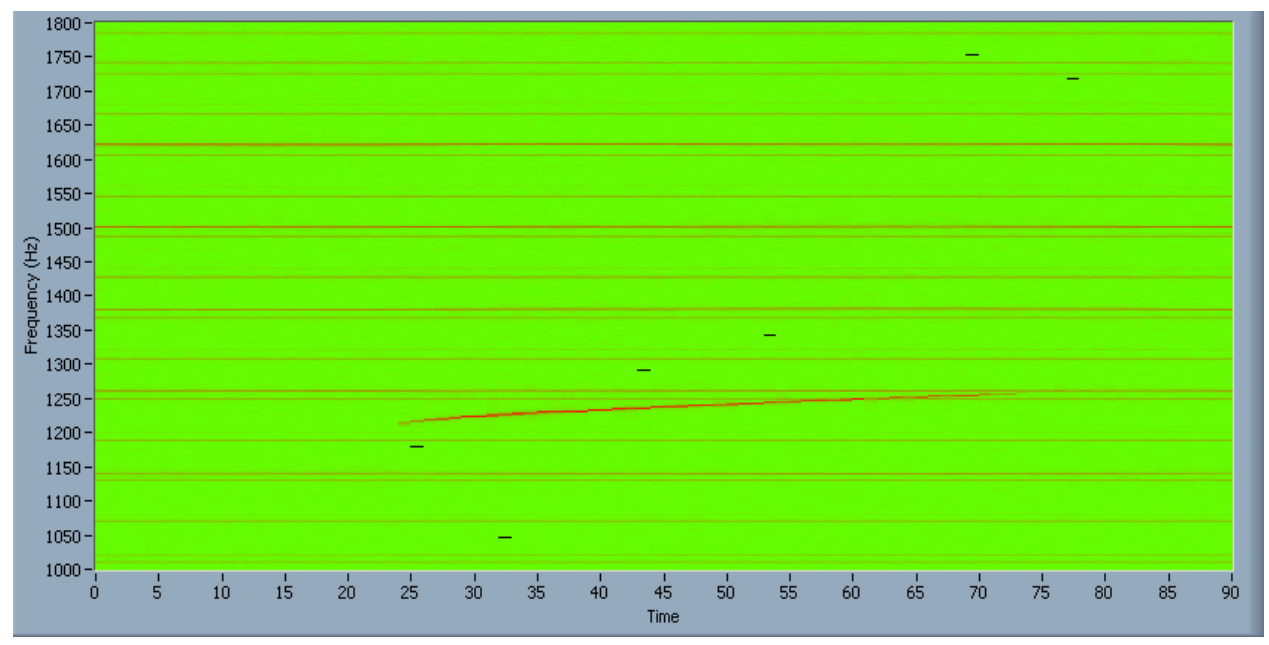

Figure 10. Spectrogram of the TAPS acquired by SSAS in sodium at $76.8^{\circ} \mathrm{C}$. 


\subsection{In-Sodium Prototype Testing and Performance Evaluation}

In-sodium tests of the TAPS prototype were conducted to evaluate the stability and performance of a TAPS operated in a sodium environment. The TAPS test apparatus has two HT shut-off valves for sodium input and output that are used to isolate the apparatus from the USV sodium loop. While running under the isolated unpumped mode, the TAPS test vessel was isolated from the USV sodium loop with these two valves shut off.

According to analysis, the resonant frequency of a TAPS shifts linearly with the change of the temperature difference between the hot side (heating temperature) and cold side of the ceramic stack. A TAPS prototype, fabricated and supplied by Westinghouse, was installed into the TAPS test vessel for in-sodium testing and performance evaluation. An array of accelerometers and a high-temperature SSAS were used to measure the acoustic resonance generated by the TAPS prototype.

\subsubsection{In-Sodium Test of TAPS in Solid Sodium}

The prototype was first tested in solid sodium at a bulk temperature $76.8^{\circ} \mathrm{C}$ as measured by the TC inside of the test vessel with the DC power supply set at $13.1 \mathrm{~V}$ and $4.93 \mathrm{~A}$. Figure 10 shows a spectrogram, acquired by the SSAS, of the TAPS prototype in sodium at $76.8^{\circ} \mathrm{C}$. It shows that the resonance of the prototype was first measured at $1,213.2 \mathrm{~Hz}$ when its temperature measured by the TC inside the hot end of the TAPS reached $199.4^{\circ} \mathrm{C}$, and increased to $1,256.5 \mathrm{~Hz}$ when reaching $527^{\circ} \mathrm{C}$. The resonant frequency of the TAPS prototype was lower than that $(1,420 \mathrm{~Hz})$ in the cover gas test. No harmonics were detected at higher frequencies.

Unlike the clean background in cover gas test shown in Figure 9, in-sodium testing showed that there is strong electromagnetic interference (EMI) and/or systematic harmonics from the environment. A signal postprocessor was added to the DAQ module to isolate interferences, enhance signal conditioning, improve peak detection, and generate resonance frequency versus -temperature plots. Figure 11 shows an improved spectrogram of the acoustic signal detected by the SSAS after postprocessing with spectral subtraction, band-pass filtering, and peak follower and gating methods. Figure 12 shows that the TAPS resonance frequency changes with respect to the temperature difference between TAPS and sodium. 


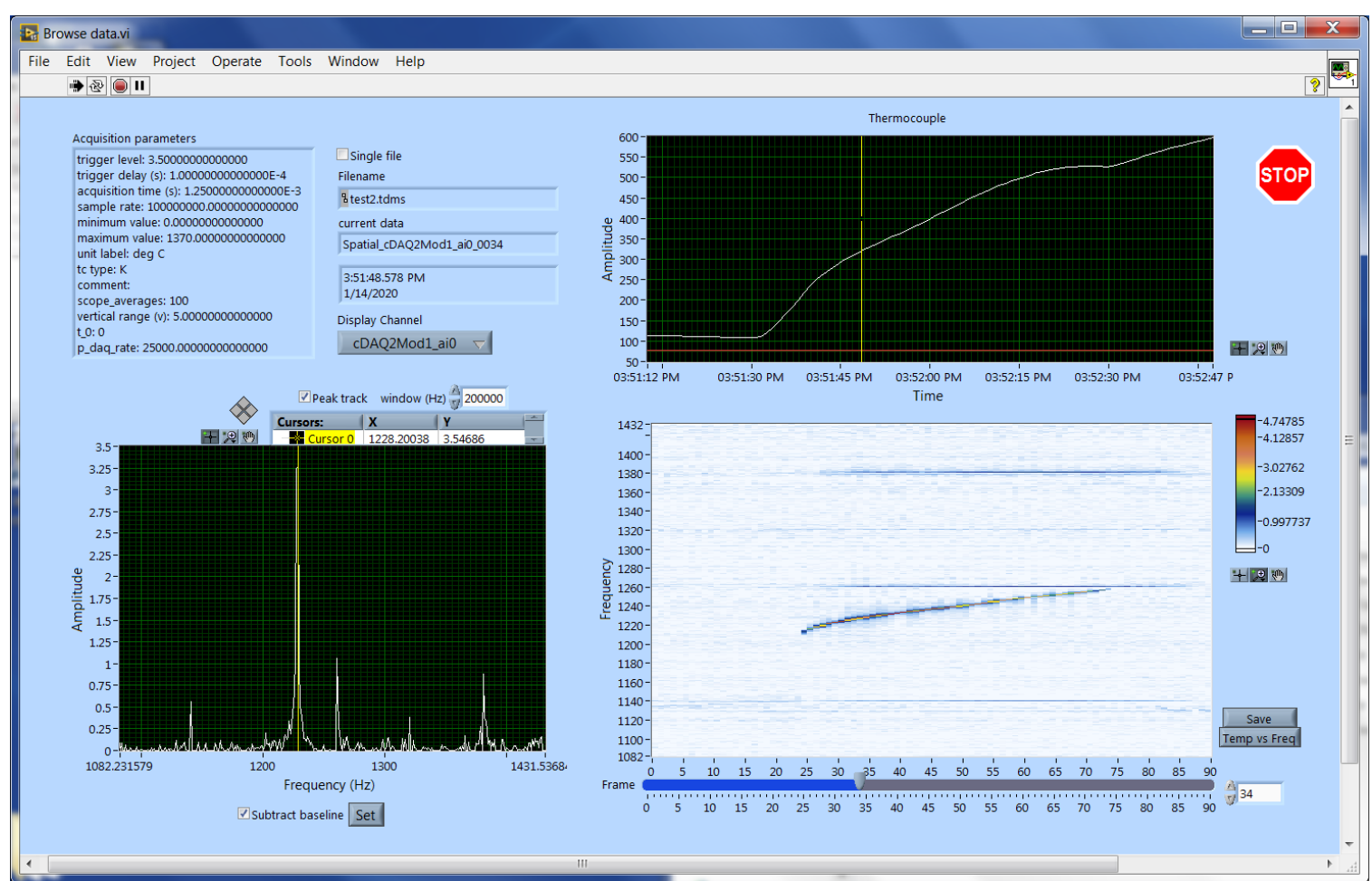

Figure 11. Bulk sodium and TAPS temperatures (top right), spectrum (bottom left), and spectrogram (bottom right) acquired by SSAS in sodium after postprocessing.

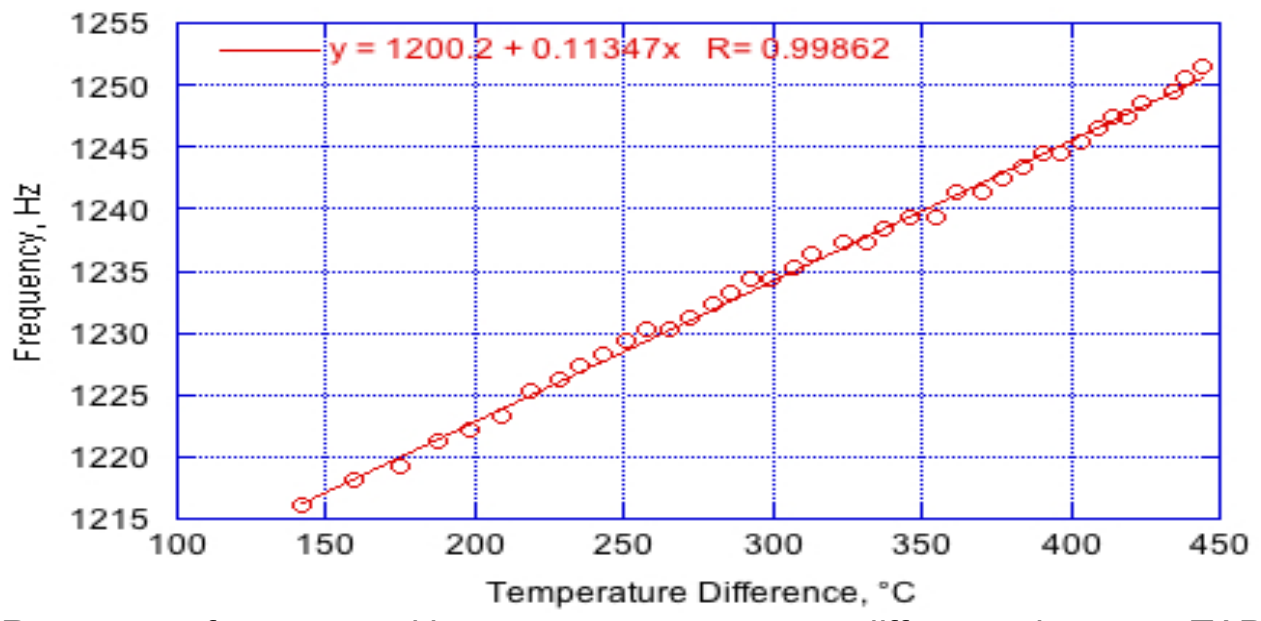

Figure 12. Resonance frequency with respect to temperature difference between TAPS and bulk sodium in sodium at $76.8^{\circ} \mathrm{C}$.

Seven of the ten accelerometers mounted on the test vessel were selected along with the SSAS submerged in the sodium. Figure 13 shows the postprocessed spectrograms, acquired by the SSAS and the seven accelerometers, of the TAPS prototype tested in sodium. All of them show similar results of the TAPS resonance frequency shifting with respect with its hot end temperature. The test verified that the TAPS prototype, the seven accelerometers, and the SSAS all were working properly. Accelerometers \# 3, \#5, and \#6 received strong low-frequency EMIs and \#3 also received periodic wide-band noise. 

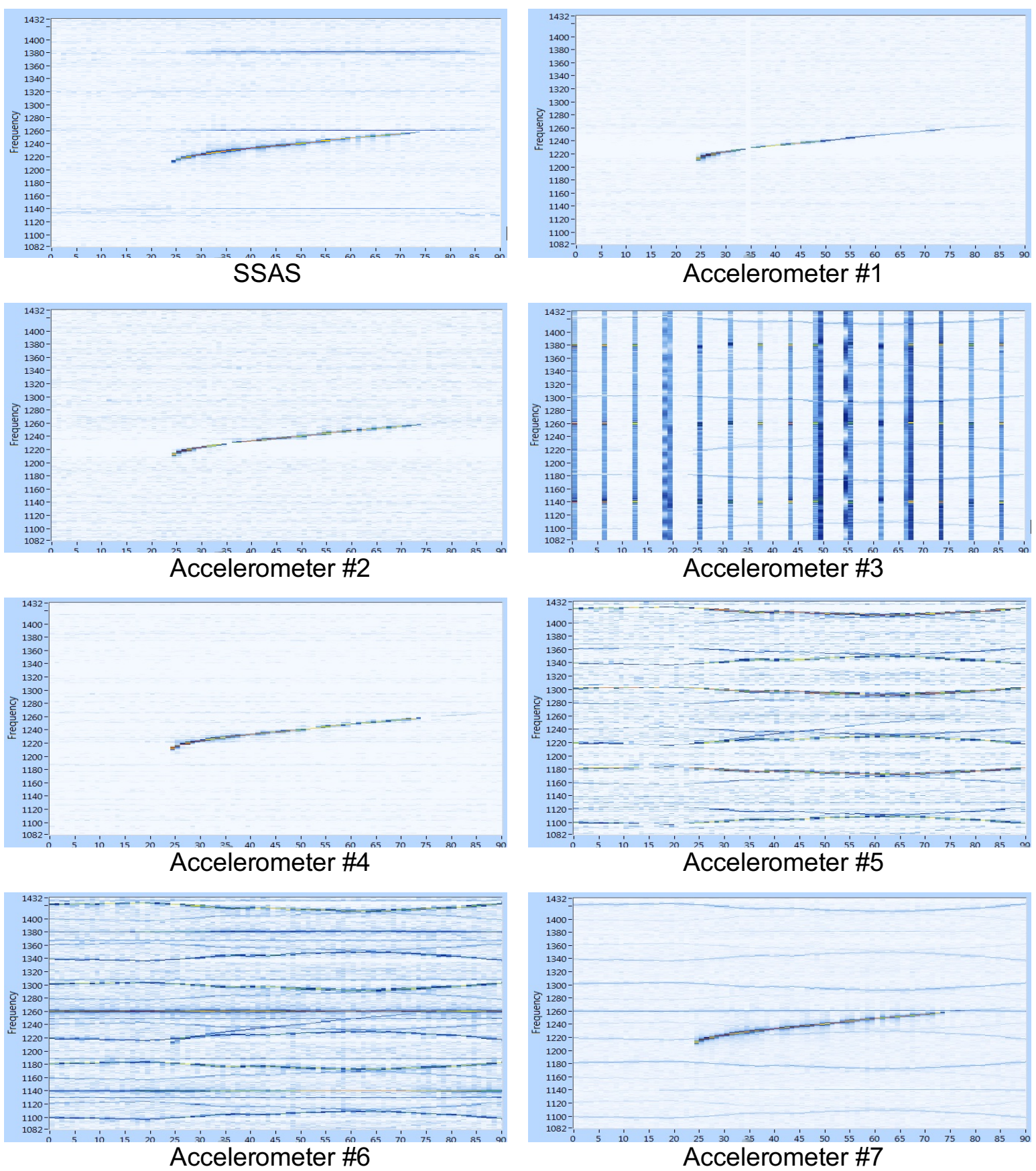

Figure 13. Postprocessed spectrograms acquired by SSAS and accelerometers in sodium at $76.8^{\circ} \mathrm{C}$.

The TAPS prototype was then tested in solid sodium at $45.2^{\circ} \mathrm{C}$ with the $\mathrm{DC}$ power supply set at $13.2 \mathrm{~V}$ and 4.9A. Figure 14 shows sensor and sodium temperatures, spectrogram, and spectrum of the TAPS acquired by the SSAS. The spectrogram was generated in real-time with background subtraction, which reduced the background interference greatly. Figure 15 shows a plot of the TAPS resonance frequency changing with respect to the temperature difference between the TAPS and bulk sodium. 


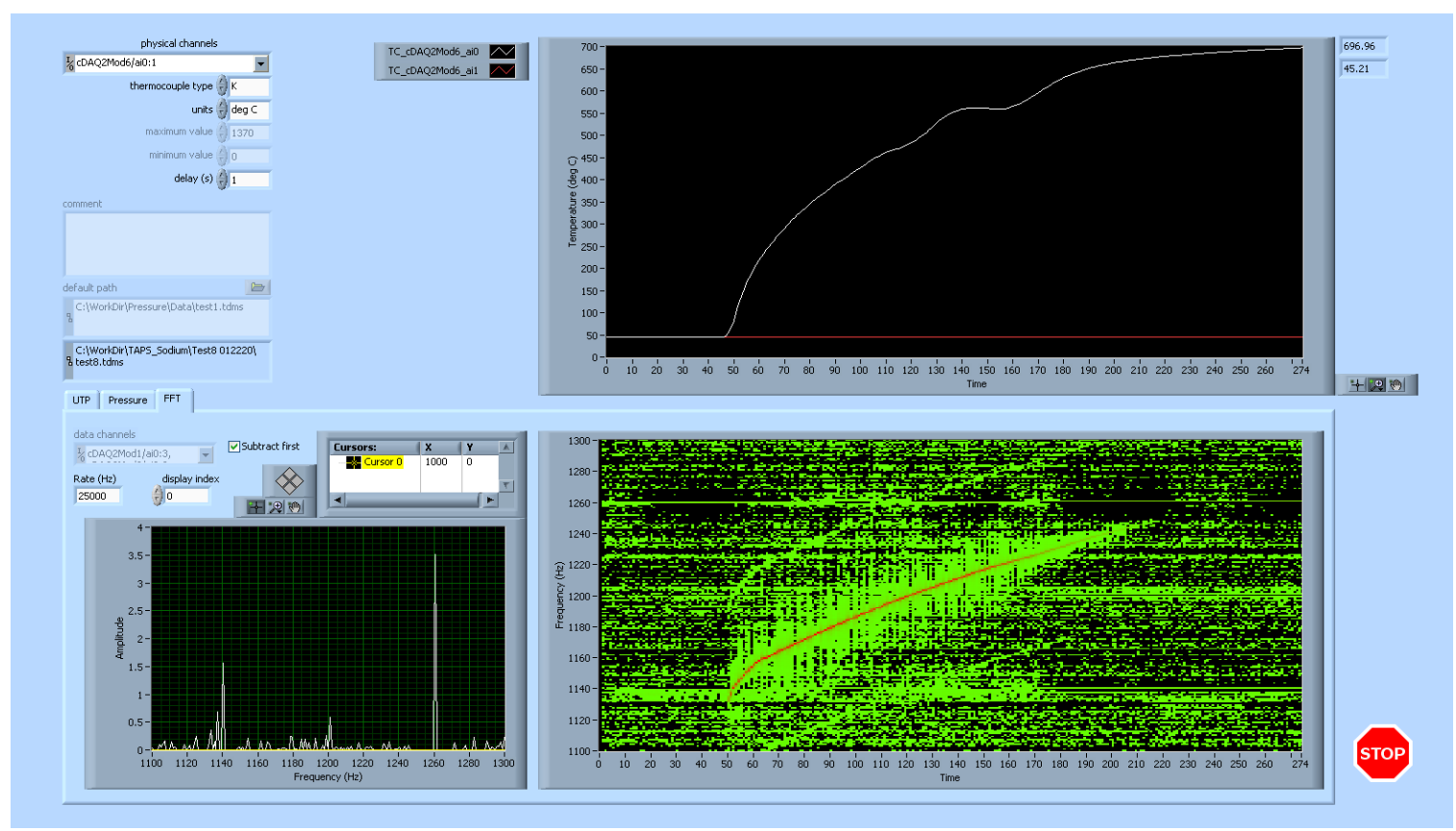

Figure 14. Sodium and TAPS temperatures (top right), spectrum (bottom left), and spectrogram (bottom right) of the TAPS acquired by SSAS in sodium at $45.2^{\circ} \mathrm{C}$.

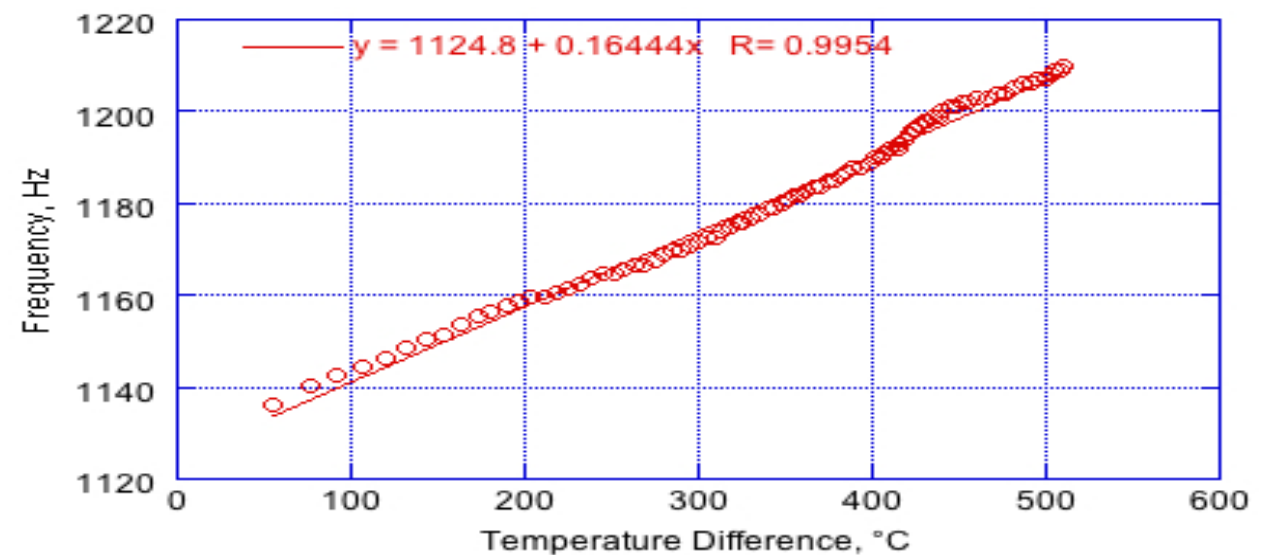

Figure 15. Resonance frequency versus temperature difference between TAPS and bulk sodium in solid sodium at $45.2^{\circ} \mathrm{C}$.

Figure 16 shows the postprocessed spectrograms, acquired by the SSAS and the seven accelerometers. Accelerometer \#1 shows minimum EMI and background noise. The strong alternating current (AC) EMI shown in some of the accelerometers previously has been eliminated through filtering and better facility grounding. The unknown periodical acoustic interferences or vibration detected by accelerometer \#3 previously has also disappeared. Besides the SSAS, all of the accelerometers detected some sort of lowintensity vibration during the middle of the test. This indicates that, compared to the accelerometers, the SSAS is less affected by vibration in the facility environment. The prototype failed to resonate continuously. The resonance became weaker, then quickly diminished when the prototype's temperature approached its operating temperature. 

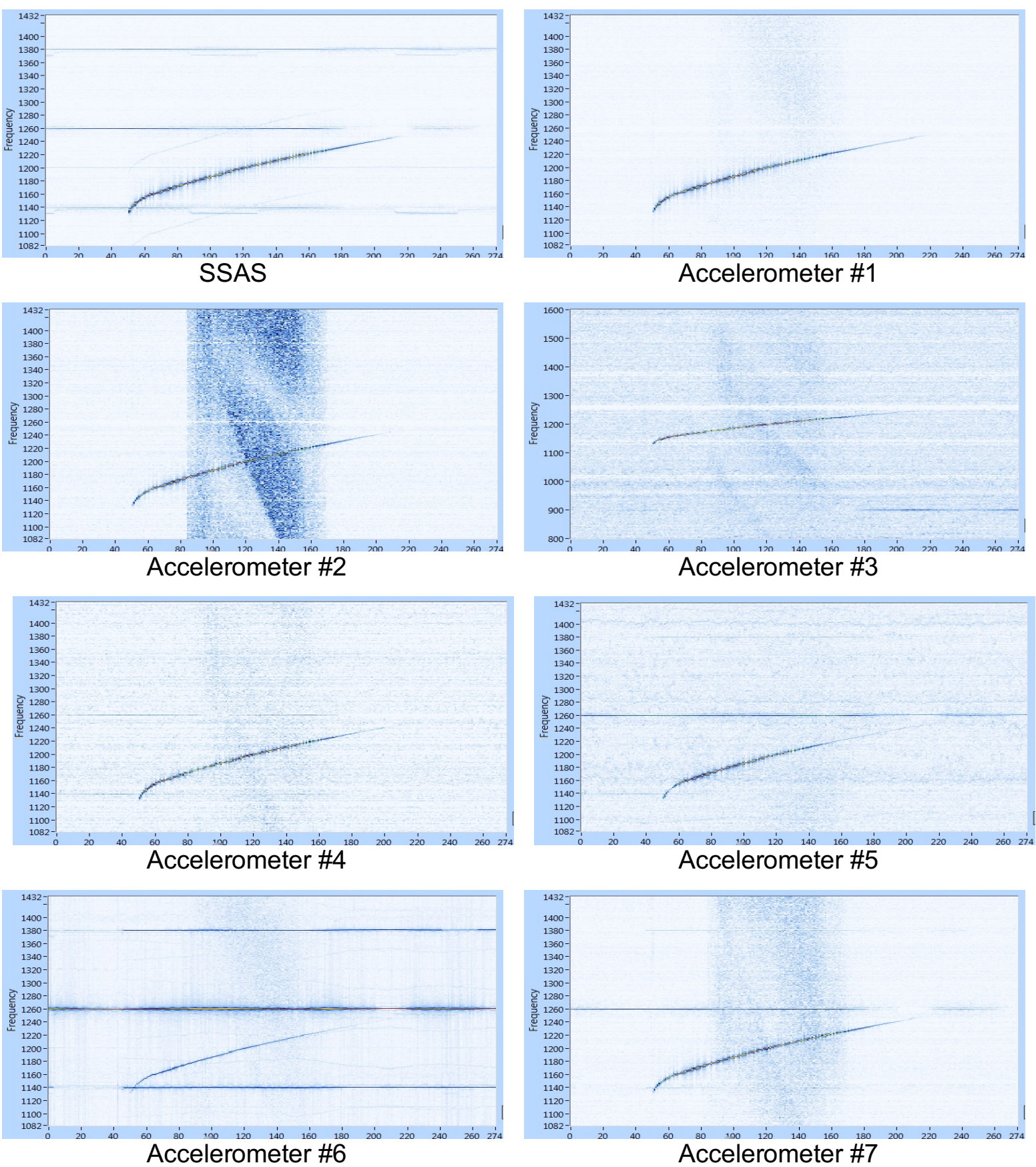

Figure 16. Postprocessed spectrograms acquired by SSAS and accelerometers in solid sodium at $45.2^{\circ} \mathrm{C}$.

\subsubsection{In-Sodium Test of TAPS in Molten Sodium}

In-sodium tests of the TAPS prototype were conducted in molten sodium at a bulk temperature of $128.4^{\circ} \mathrm{C}$ with the DC power supply of the TAPS's internal heater set at $13.1 \mathrm{~V}$ and 4.86A. Figure 17 shows TAPS and sodium temperatures, resonance, and spectrograms, acquired by the SSAS in real time. When reaching above $\sim 336^{\circ} \mathrm{C}$, the prototype started to resonate at a frequency of $\sim 1,266.7 \mathrm{~Hz}$. The resonance frequency rose linearly with the TAPS's temperature, but stopped resonating when the temperature was above 
$\sim 422^{\circ} \mathrm{C}$. The prototype did not establish a continuous resonance at high temperature or close to its operating temperature. The prototype was then cooled down after turning the power supply off. After being reheated, the prototype started resonating accordingly at about the same TAPS temperature and frequency, but still failed to establish a continuous resonance. Figure 18 shows TAPS resonance frequencies changing with respect to the temperature difference between the TAPS and the bulk sodium of the two consecutive tests in molten sodium. The resonant frequencies of the two tests have the same slopes but are offset by $2 \mathrm{~Hz}$. Figure 19 shows postprocessed spectrograms of the TAPS prototype acquired by the SSAS and the seven accelerometers. Somehow, accelerometer \#5 and \#6 received low-frequency interferences, which had higher intensities and did not get filtered out by both the analog and digital filters that was added into the I\&C unit.

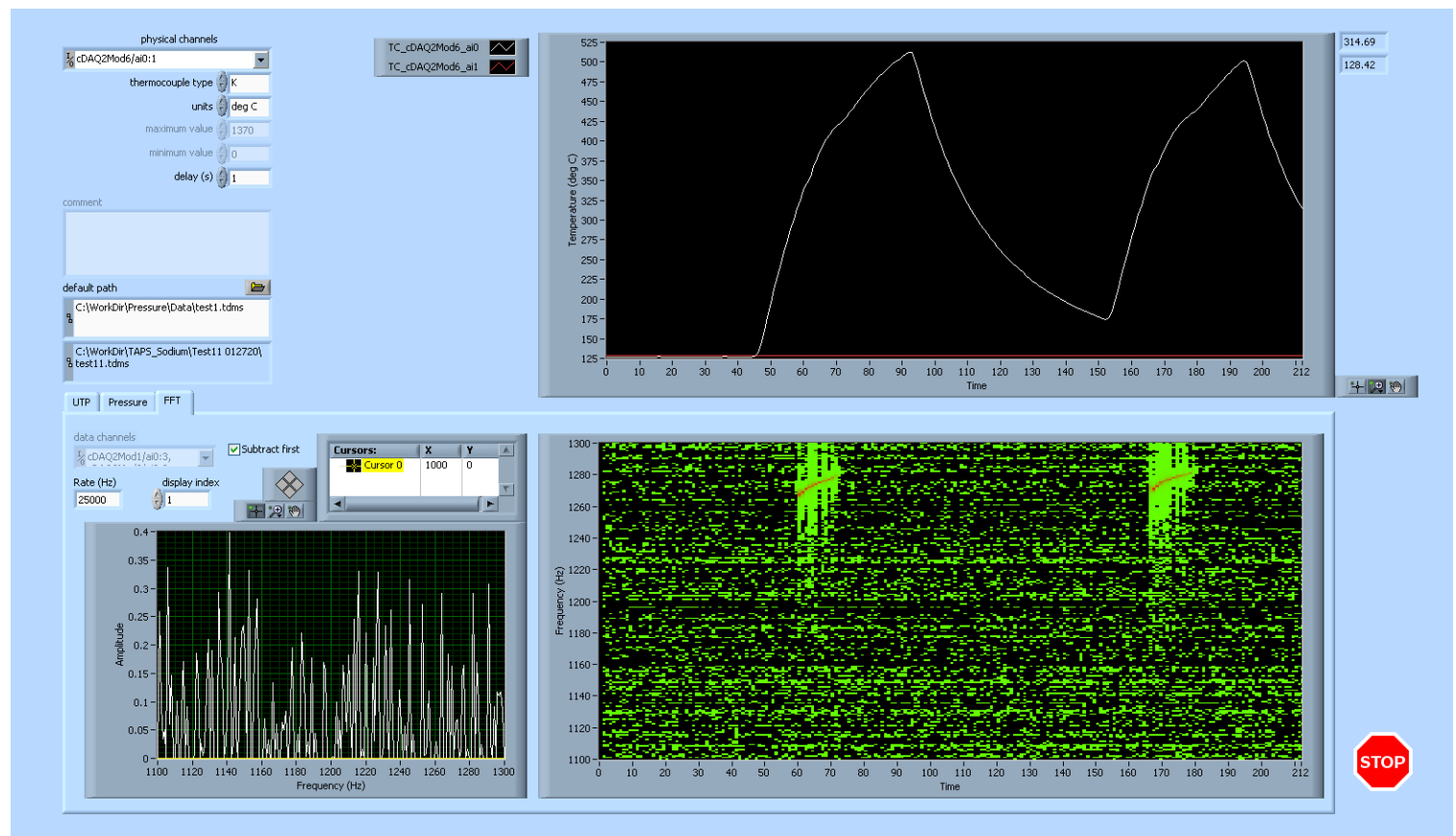

Figure 17. Bulk sodium and TAPS temperatures, spectrogram, spectrum, and resonance of TAPS detected by accelerometer \#4 in sodium after postprocessing of test TAPS-LT2.

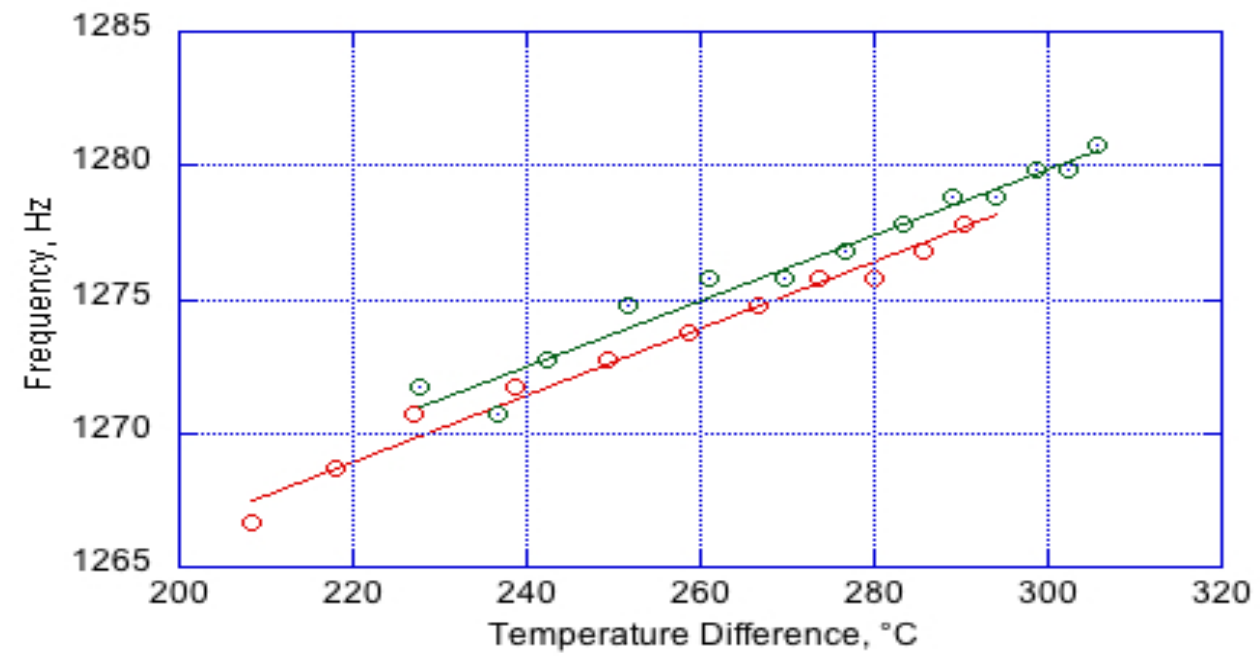

Figure 18. Resonant frequencies of two consecutive tests with respect to temperature difference between TAPS and bulk sodium in molten sodium at $128.4^{\circ} \mathrm{C}$. 

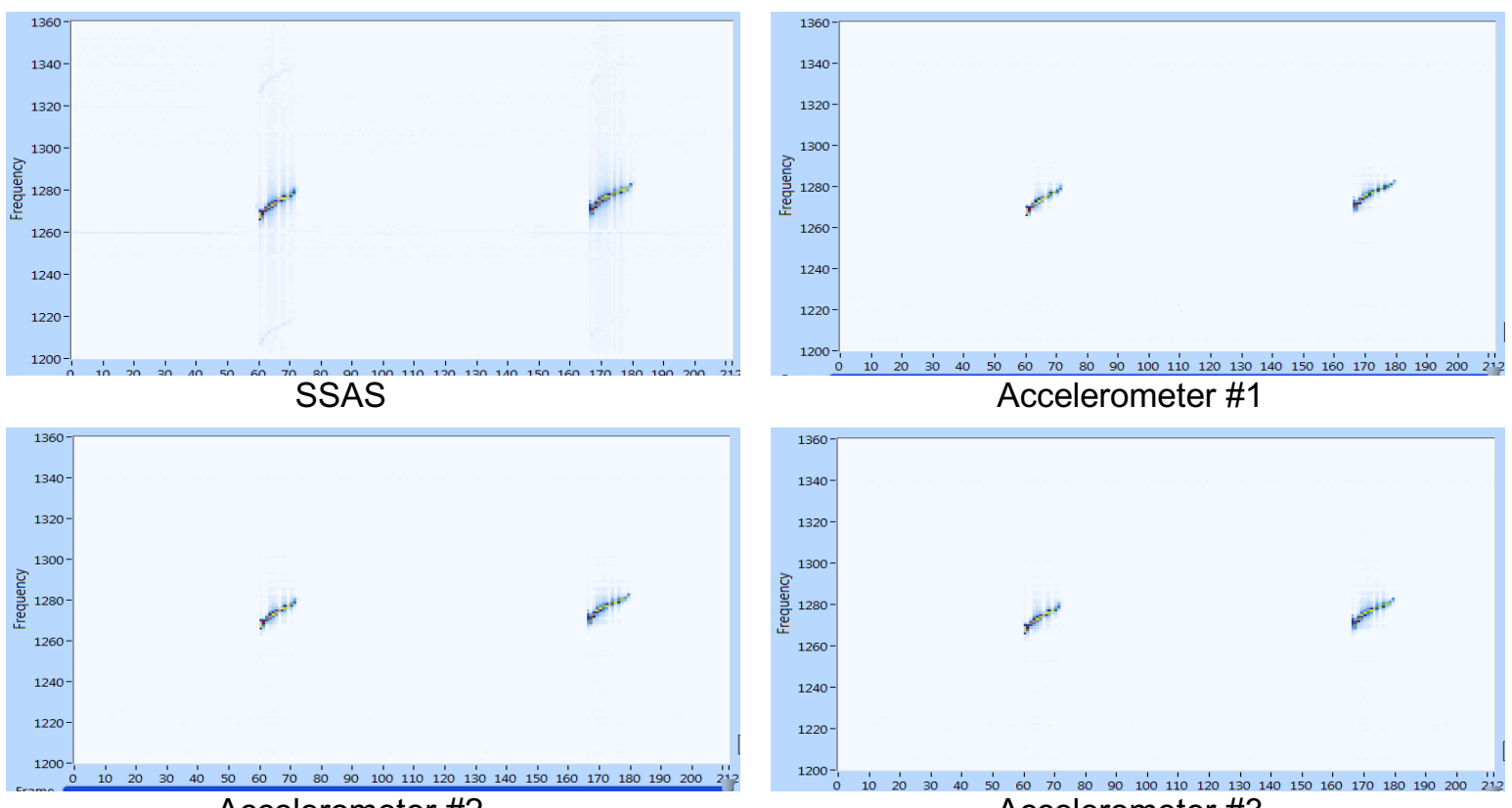

Accelerometer \#2
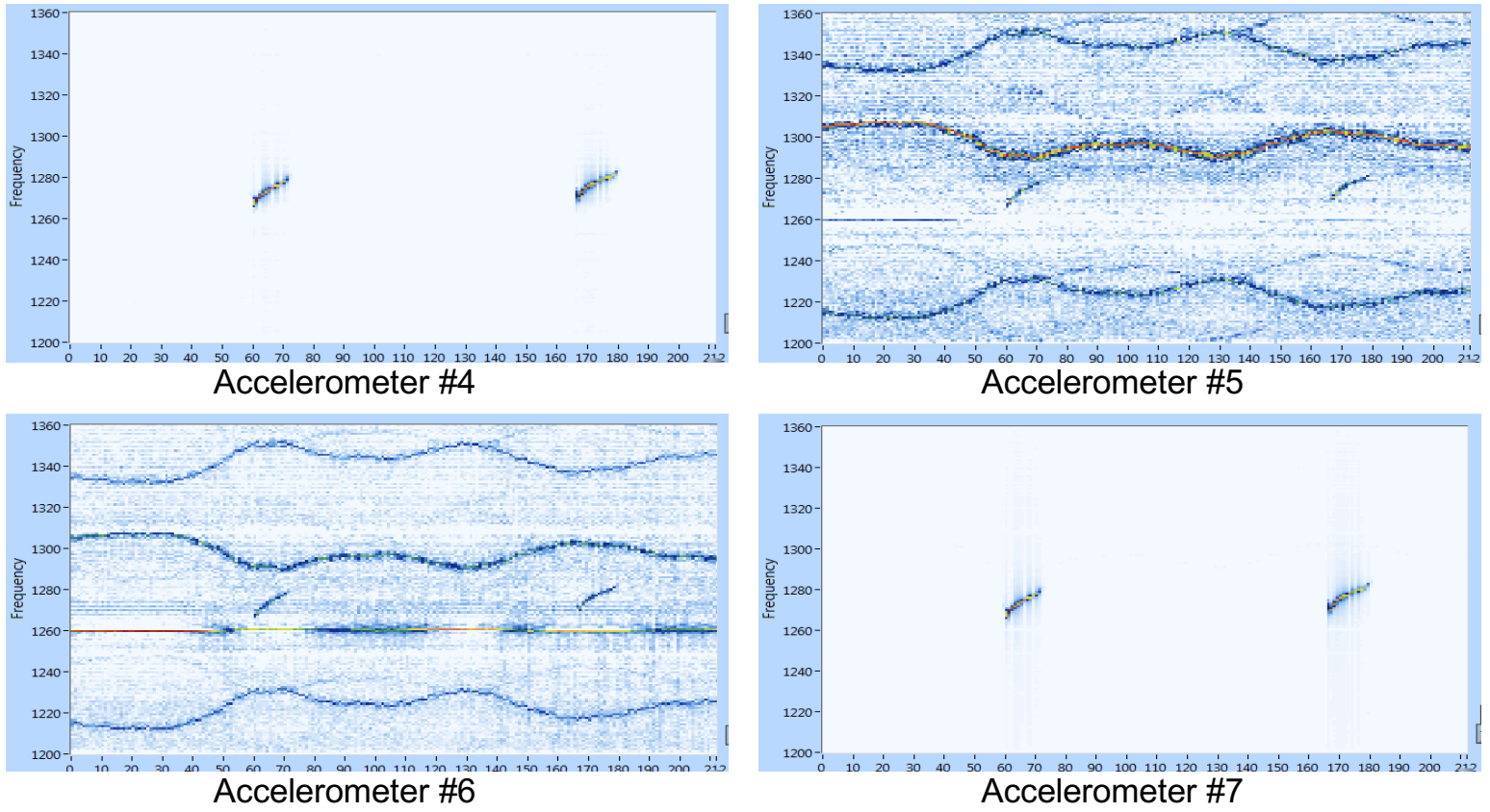

Figure 19. Spectrograms acquired by SSAS and accelerometers in molten sodium at $128.4^{\circ} \mathrm{C}$.

\subsubsection{In-Sodium Test of TAPS with Continuous Resonance}

After immersion in sodium at $167^{\circ} \mathrm{C}\left(350^{\circ} \mathrm{F}\right)$ for several weeks, the TAPS prototype was able to establish a continuous resonance but only in solid sodium. It was suspected that sodium wetting of the TAPS prototype might not have fully developed. A series of tests of the TAPS prototype were conducted in solid sodium at different TAPS operating temperatures, i.e., operating under different DC voltages. Table 2 lists the TAPS operating temperature and quality of resonance intensity of the SSAS and accelerometers of the ten in-sodium tests of the TAPS prototype at $51.5^{\circ} \mathrm{C}$. Accelerometers $\# 3$ and $\# 6$ failed to respond. This might be caused by bonding failures of the accelerometers' mounting bases. 
Table 2: Operating Condition and Signal Quality of TAPS Tested in Sodium

\begin{tabular}{lcccccccc}
\hline File Name & $\mathrm{T}\left({ }^{\circ} \mathrm{C}\right)$ & $\begin{array}{c}\text { Continuous } \\
\text { Resonance }\end{array}$ & $\begin{array}{c}\text { Acoustic } \\
\text { Sensor }\end{array}$ & $\begin{array}{c}\text { Accel. } \\
\# 1\end{array}$ & $\begin{array}{c}\text { Accel. } \\
\# 2\end{array}$ & $\begin{array}{c}\text { Accel. } \\
\# 4\end{array}$ & $\begin{array}{c}\text { Accel. } \\
\# 5\end{array}$ & $\begin{array}{c}\text { Accel. } \\
\# 7\end{array}$ \\
\hline TAPS-LT & $50-350$ & Yes & Good & Fair & $\mathrm{X}$ & Good & $\mathrm{X}$ & Poor \\
TAPS-LT1 & $50-300$ & Yes & Good & Fair & Poor & Good & Poor & Fair \\
TAPS-LT2 & $50-300$ & Yes & Fair & Good & Fair & Good & Poor & Fair \\
TAPS-LT3 & $50-500$ & $\mathrm{X}$ & $\mathrm{X}$ & $\mathrm{X}$ & $\mathrm{X}$ & $\mathrm{X}$ & $\mathrm{X}$ & $\mathrm{X}$ \\
TAPS-LT4 & $50-500$ & No & Poor & Poor & $\mathrm{X}$ & Fair & $\mathrm{X}$ & $\mathrm{X}$ \\
TAPS-LT5 & $50-425$ & Yes & Good & Poor & $\mathrm{X}$ & Poor & $\mathrm{X}$ & $\mathrm{X}$ \\
TAPS-LT6 & $50-400$ & Yes & Fair & Poor & $\mathrm{X}$ & Fair & $\mathrm{X}$ & $\mathrm{X}$ \\
TAPS-LT7 & $50-400$ & Yes & Good & Poor & $\mathrm{X}$ & Poor & $\mathrm{X}$ & $\mathrm{X}$ \\
TAPS-LT8 & $50-400$ & Yes & Poor & Poor & $\mathrm{X}$ & Fair & $\mathrm{X}$ & $\mathrm{X}$ \\
TAPS-LT9 & $50-400$ & Yes & Fair & Poor & $\mathrm{X}$ & Fair & $\mathrm{X}$ & $\mathrm{X}$ \\
TAPS-LT10 & $50-400$ & Yes & Fair & Poor & $\mathrm{X}$ & Good & $\mathrm{X}$ & $\mathrm{X}$ \\
\hline
\end{tabular}

Test TAPS-LT1 was the first in-sodium test of the TAPS prototype that could establish a continuous resonance. It also repeatedly established continuous and consistent resonances when cycling its controlling DC voltage, i.e., operating temperature. For an unknown reason, comparing with the previous tests, the resonant frequency of the TAPS prototype shifted higher to $1,940 \mathrm{~Hz}$ or even $2,040 \mathrm{~Hz}$ in two tests. Figure 20 shows TAPS TC and bulk sodium temperatures, spectrogram, and spectrum of the TAPS acquired by the SSAS. When the TAPS's DC power supply was turned off and on at the end of the test, the TAPS's temperature dropped and recovered accordingly and its resonance also recovered to the sane frequency. Continuous and consistent resonance was established until the DC power supply was turned off.

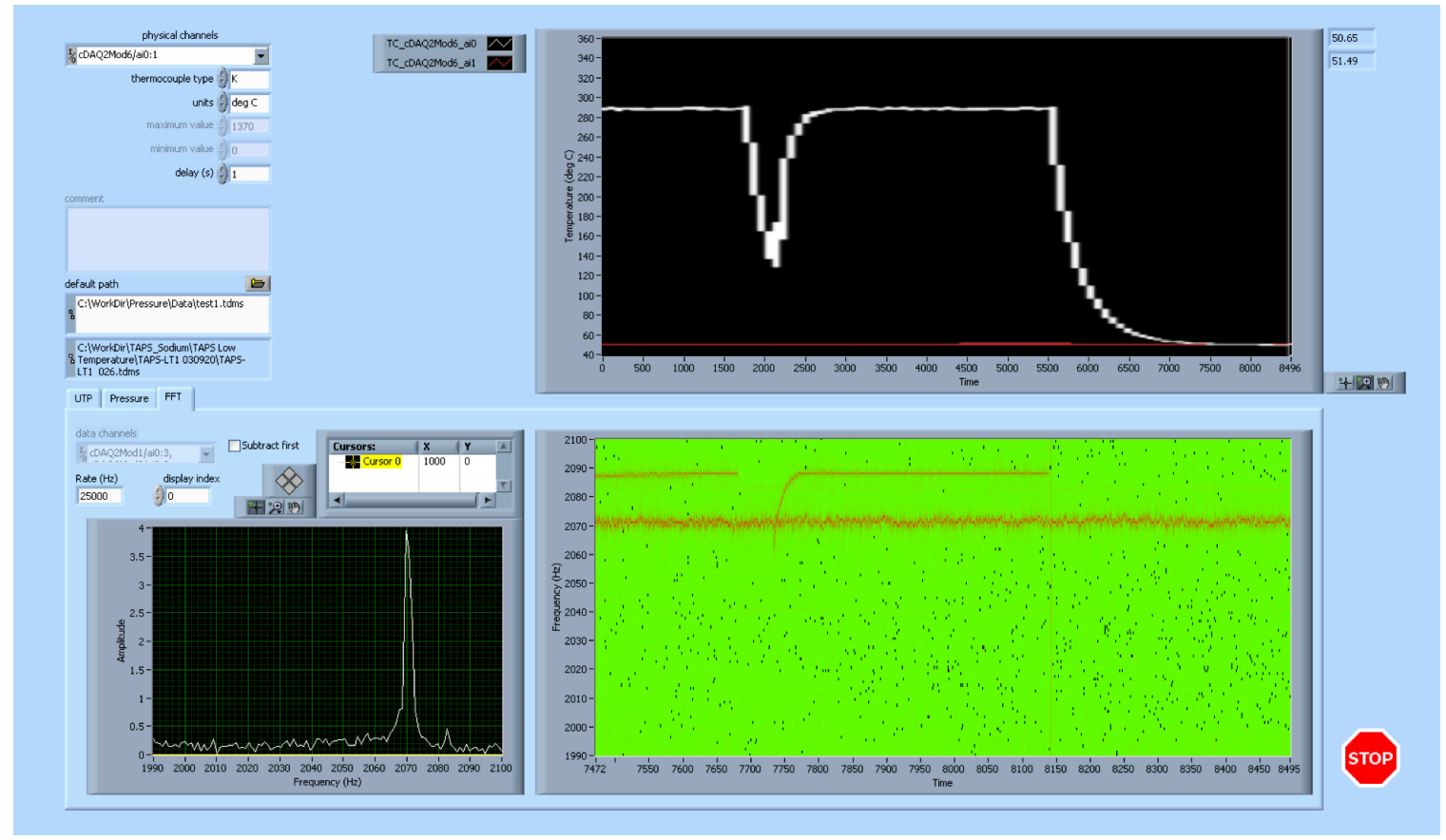

Figure 20. Bulk sodium and TAPS temperatures (top right), spectrum (bottom left), and spectrogram (bottom right) acquired by SSAS in sodium at $51.5^{\circ} \mathrm{C}$. 
Figure 21 shows TAPS and sodium temperatures, spectrogram, spectrum, and resonance of the TAPS acquired by accelerometer \#4 in sodium at $51.3^{\circ} \mathrm{C}$ after postprocessing of test TAPS-LT2. Figure 22 shows postprocessed spectrograms of the TAPS prototype acquired by the SSAS and three accelerometers (\#1, \#4, and \#7). The TAPS resonance acquired by the SSAS was coupled with acoustic noise in the test environment while that of the three accelerometers was not. From the results shown in Figures 16 and 22, because of the nature of detection principles and mounting methods, the SSAS is more affected by acoustic noise, while accelerometers are more affected by vibrations in the environment. Figure 23 shows postprocessed spectrograms of different in-sodium tests of the TAPS prototype acquired by accelerometer \#4. Figure 24 shows TAPS resonance frequencies changing with respect to the temperature difference between the TAPS and bulk sodium. The resonant frequencies of the first two tests (TAPS-LT1 and TAPSLT2) shifted $\sim 100 \mathrm{~Hz}$ higher than that of the other six tests.

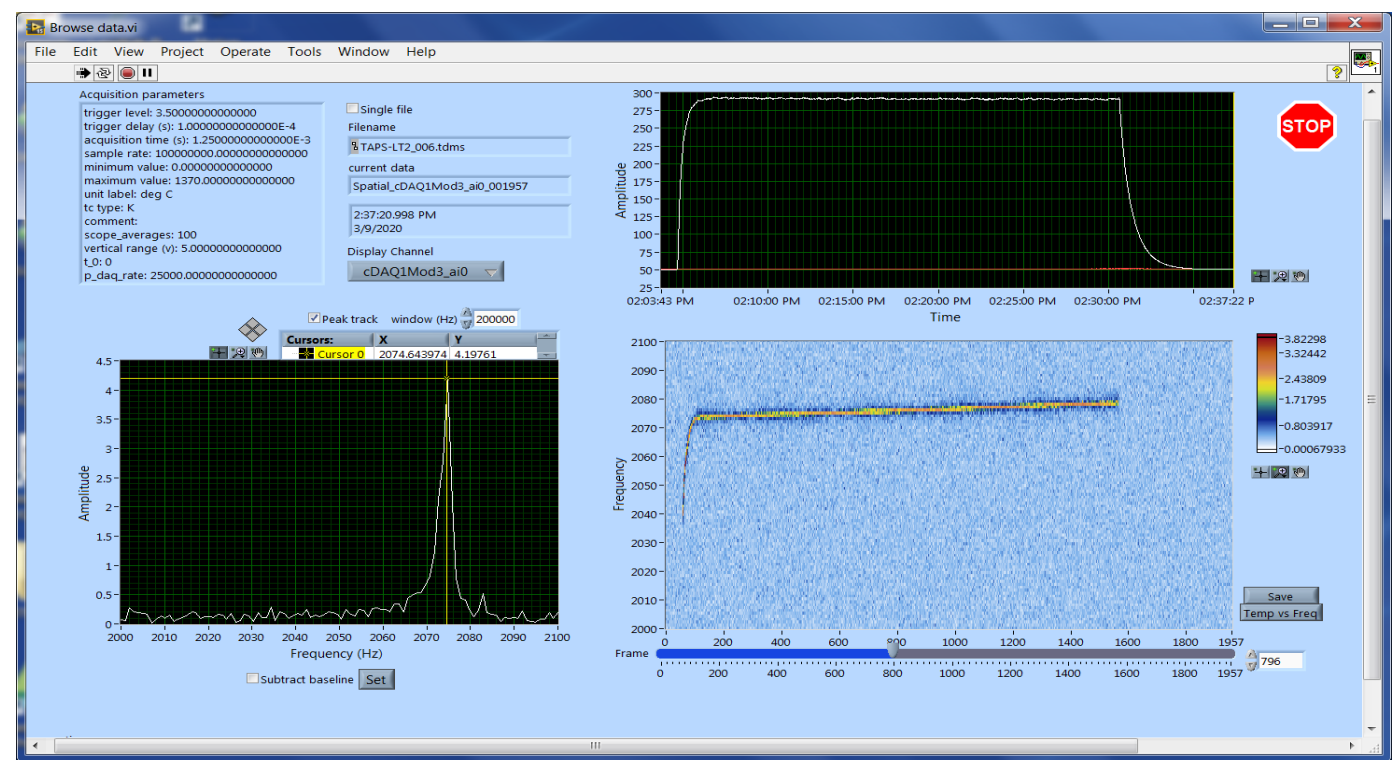

Figure 21. Bulk sodium and TAPS temperatures, spectrum, and spectrogram, of TAPS prototype detected by accelerometer \#4 in sodium after postprocessing of test TAPS-LT2.
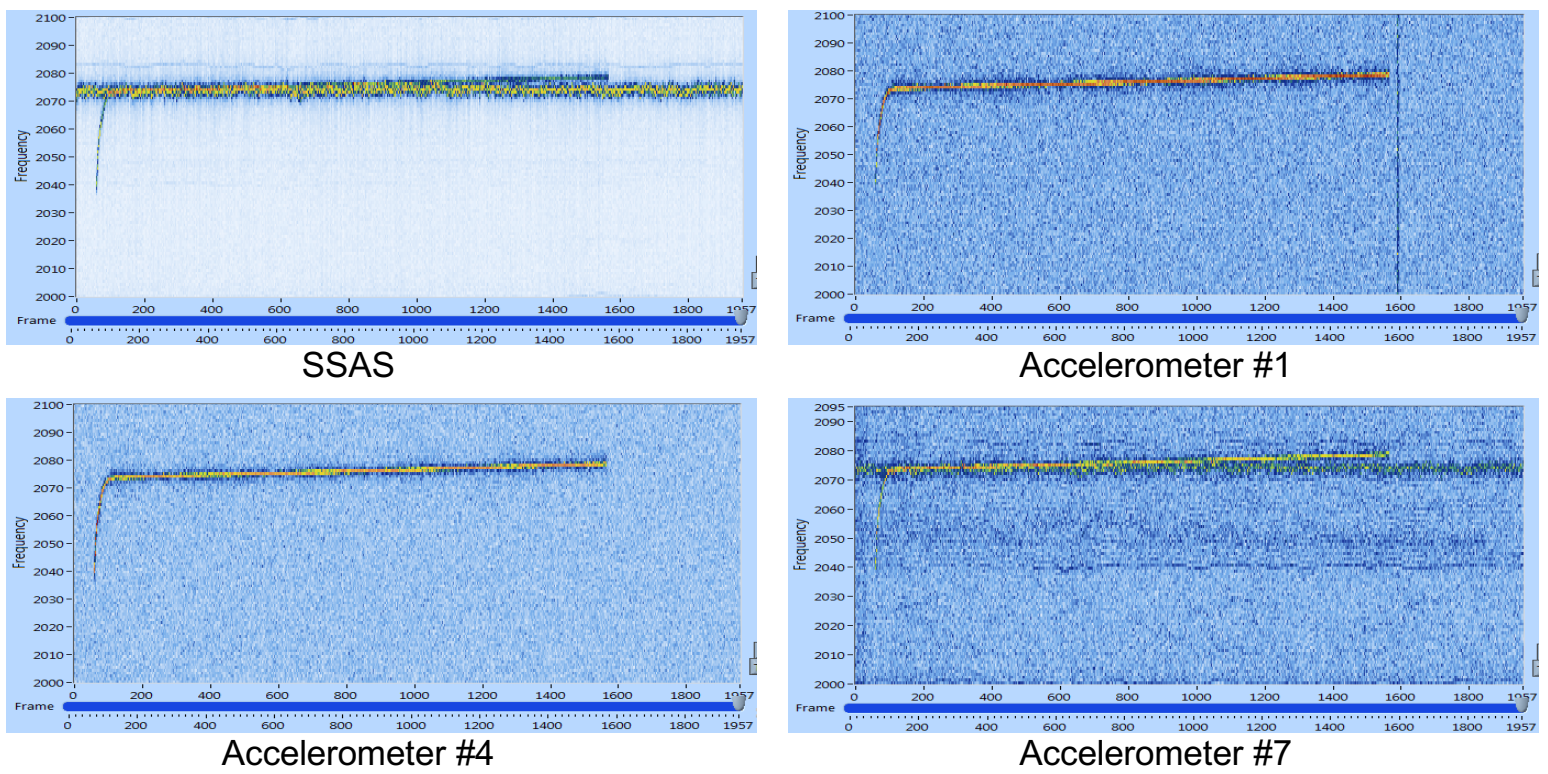

Figure 22. Spectrograms of the TAPS acquired by SSAS and accelerometers of test TAPS-LT2. 

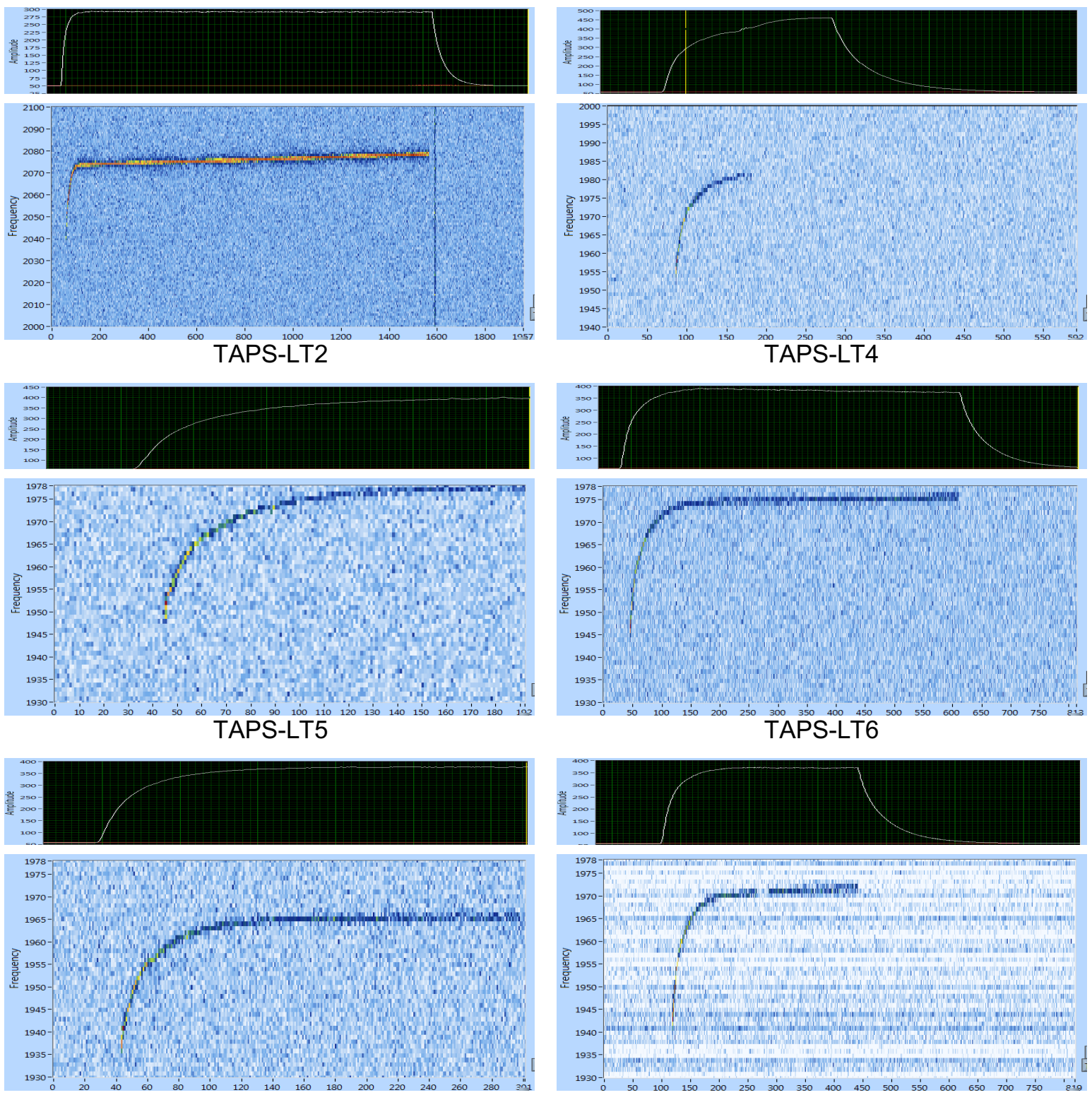

TAPS-LT7
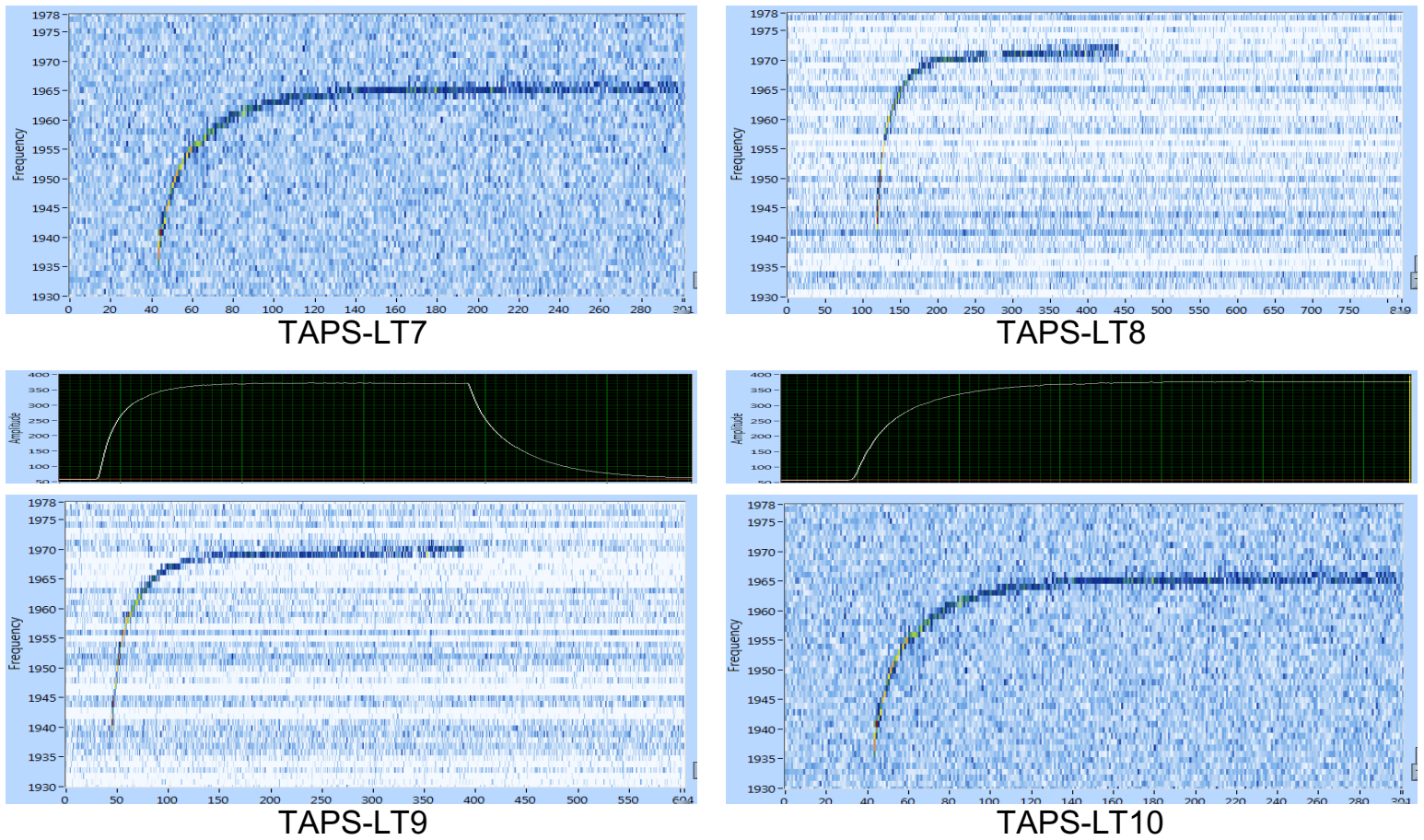

Figure 23. TAPS's temperature and spectrograms acquired by accelerometer \#4 for eight different tests in sodium at $51.5^{\circ} \mathrm{C}$. 


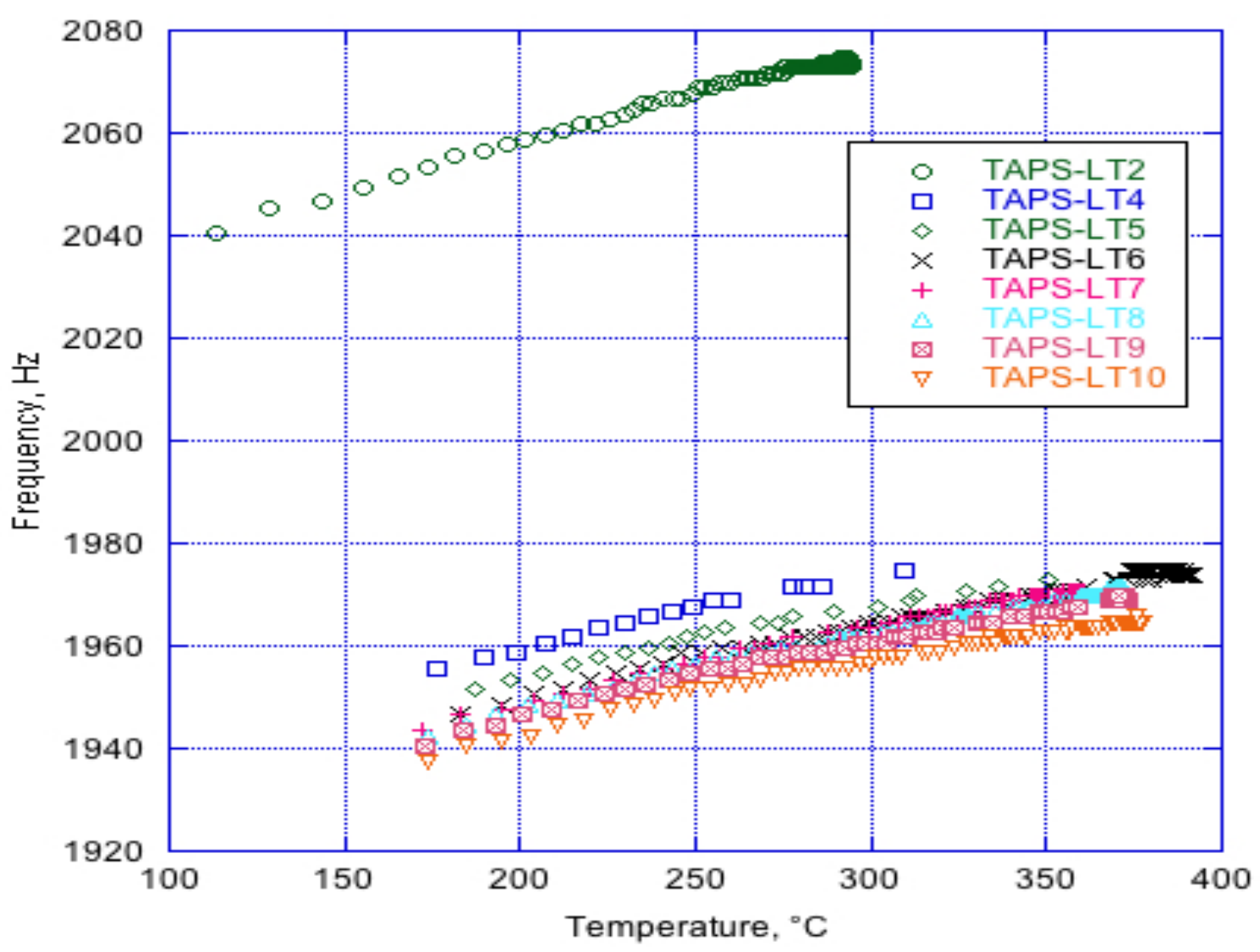

Figure 24. Resonant frequencies acquired by accelerometer \#4 of in-sodium TAPS tests.

\section{$6 \quad$ POST IN-SODIUM TESTS AND FAILURE MODES ASSESSMENT}

Due to the COVID-19 pandemic and shutdown of most activities at Argonne, the in-sodium testing of the TAPS prototype was suspended for four months. The TAPS prototype was submersed in molten sodium at $149^{\circ} \mathrm{C}\left(300^{\circ} \mathrm{F}\right)$ during the Laboratory shutdown. After the restart of in-sodium testing, the TAPS prototype failed to resonate at all. The TAPS is a passive acoustic resonance device which consists of a resonator filled with helium-argon gas mixture, a heating element with a TC, a thermal insulator at the hotend, and a ceramic stack. From a failure modes assessment, potential causes of the failure were identified as the following:

a) Too small temperature difference: The prototype generates acoustic waves when the temperature difference between its hot and cold ends is greater than $150^{\circ} \mathrm{C}$. If the heat conducted from the hot end to the cold end can't be removed fast enough, causing the temperature gradient to decrease, the resonance intensity would become weaker. Alternately, the TAPS with its internal heater is a localized heat source inside of the bulk sodium inside of the test vessel. As that heat source increases, it is expected to give rise to increasing natural convection of the bulk sodium upward along the TAPS. The convecting sodium may remove heat from the TAPS tending to lessen the temperature difference from the top to the bottom of the ceramic stack. When the temperature difference across the stack drops to a certain level, the resonance would diminish;

b) Ceramic stack broken or blocked: The ceramic stack functions as a thermal insulator to maintain a temperature gradient between the hot and cold ends, as well as guiding the thermoacoustic waves 
to oscillate between the hot and cold ends. If it is broken or blocked, the waves can't oscillate across the stack and produce standing thermoacoustic waves.

c) Gas leaking out: The prototype is filled with a helium/argon gas mixture (80/20 ratio). Helium has very high thermal conductivity. If the gas mixture or helium in the gas mixture leaks out as by leakage through a seal or diffusion through the TAPS wall, then the gas density would drop and might weaken or stop the standing thermoacoustic wave oscillation. Preferential diffusion of helium through the seal or TAPS wall would reduce the gas thermal conductivity.

d) Heater failure: The prototype uses an electric heater as a heating source to maintain a consistent operating temperature at the hot end, i.e., to generate a consistent resonant frequency. If the heater fails to produce a consistent heating, the standing thermoacoustic wave oscillation might be weakened or diminished completely.

To obtain further information potentially relevant to the cause of the failure, different post in-sodium tests have been conducted.

\section{Post In-sodium Test in Cover Gas}

The TAPS prototype was tested in cover gas before submersing into sodium. As presented in Section 5.1, the prototype was able to generate a continuous and consistent resonance at $1407.2 \mathrm{~Hz}$ when operating at $590^{\circ} \mathrm{C}$. The test vessel has an extension cap mounting on the top flange such that the prototype can be lifted out of the liquid sodium and removed from the test vessel. To assess the cause of the failure, the first post in-sodium test conducted was to lift and test the prototype in cover gas. Unfortunately, operating at different TAPS operating temperatures, the prototype did not resonate at all in cover gas at $149^{\circ} \mathrm{C}\left(300^{\circ} \mathrm{F}\right)$.

\section{Post In-sodium Test in Water}

Since the prototype did not resonate in cover gas, we decided to remove it from the test vessel and test it in water. The sodium in the test vessel was drained into the dump tank. After the vessel cooled down, the extension cap was then covered inside a glove bag that was filled with argon gas to avoid sodium contamination while removing the cap flange and the prototype. The prototype was put inside a metal pipe in the scrub room for several days. After the residual sodium hydrated, the prototype was submersed in alcohol and cleaned with acetone. The prototype was tested in distilled water. It still did not resonate.

\section{Internal and External Integrity Examination}

By examining the exterior of the prototype, we did not find any damage. However, there is some kind of rattling sound when turning it upside down. An x-ray of the prototype might be able to examine its internal integrity. The seal location where the helium-argon gas mixture could leak out is through the heater and TC lead connection ports. It is not possible to examine the ports unless the SS protection tube is cut off. An alternative is to measure the speed-of-sound by using an ultrasonic technique to determine the gas composition of the gas mixture.

\section{$\underline{\text { Heater diagnosis }}$}

The prototype was operated with a consistent DC power supply setting (13.1V and 4.93A). The operating temperature of the hot end attained over $500^{\circ} \mathrm{C}$. During the post in-sodium test in water, the operating temperature could only reach $\sim 300^{\circ} \mathrm{C}$, which theoretically should generate a temperature gradient that is large enough to initiate a resonance, but it didn't. 


\section{DISCUSSION AND SUMMARY}

Argonne completed the construction of a TAPS test apparatus and successfully integrated it with the upgraded USV sodium test facility. The integrated USV-TAPS sodium test facility has been operational for in-sodium testing of the TAPS. Argonne received a TAPS prototype from Westinghouse and the prototype was modified such that it can be installed into the TAPS test vessel and work in sodium at elevated temperature without potentially causing sodium leaking. The prototype and a high-temperature sodiumsubmersible acoustic sensor (SSAS) developed by Argonne were both installed inside of the TAPS test vessel. Ten accelerometers were also mounted on the external wall and the top flange of the TAPS test vessel. An instrumentation and control (I\&C) system was developed for operation of the USV-TAPS facility, as well as data acquisition and analysis. A signal postprocessor was added to the DAQ module to isolate interferences, enhance signal conditioning, improve peak detection, and generate resonance frequency versus temperature plots.

For functionality verification, the TAPS prototype and the SSAS were tested within argon cover gas under ambient conditions. The prototype demonstrated that it was functioning properly with a resonant frequency at $1,407.2 \mathrm{~Hz}$, which was successfully detected by the high-temperature SSAS and all seven accelerometers. After successfully transferring sodium into the test vessel, in-sodium tests of the prototype were conducted at different sodium temperatures. Tests of the TAPS prototype demonstrated that the resonance frequency of the TAPS changes linearly with respect to the temperature difference between the TAPS and bulk sodium. The resonant frequency was lower than that obtained in a water mockup and the cover gas tests. Also, the resonance of the TAPS prototype diminished before the prototype reached its operating temperature and failed to establish a continuous resonance in sodium. After testing in molten sodium and immersion at higher temperature for several weeks, the TAPS prototype was able to establish a continuous resonance but only in solid sodium. The tests also demonstrated that, because of the nature of the detection principles and mounting methods, the high-temperature SSAS is more affected by acoustic noise, while accelerometers are more affected by vibrations, in the test environment.

It is unknown why the TAPS prototype only occasionally established a continuous and consistent resonance when the TAPS temperature reached its operating temperature in molten sodium, and why it ultimately failed to resonate at all. A failure modes assessment was conducted and a few potential causes of failure were identified. Different post in-sodium tests were conducted to obtain additional information potentially relevant to the cause of the failure. Nondestructive evaluation techniques are suggested to examine the internal integrity as well as the gas mixture of the prototype. If they prove inconclusive, the prototype should be cut open to conduct a thorough inspection of its internal integrity and determine the state of the gas mixture.

\section{REFERENCES}

1. M. D. Heibel, et. al., "Development of Thermoacoustic Sensors for Sodium-cooled Fast Reactors," Westinghouse Technical Report RT-TR-18-18, September 2018.

2. H. T. Chien, J. J. Sienick, T. W. Elmer, and W. P. Lawrence, "Demonstration of Thermoacoustic Power Sensor," Argonne National Laboratory Technical Report ANL-ART-180, September 2019.

3. "Functional Requirements for Thermo-Acoustic Sensor System for Sodium-cooled Fast Reactors," June 2015, Westinghouse Internal Report, RT-FR-15-001. 
This page intentionally left blank. 



Argonne

Nuclear Science and Engineering Division

Argonne National Laboratory

9700 South Cass Avenue, Bldg. 208

Argonne, IL 60439-4842

www.anl.gov

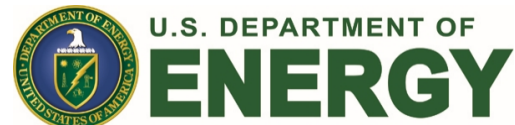

Argonne National Laboratory is a U.S. Department of Energy

laboratory managed by UChicago Argonne, LLC 